\title{
Competition and Cooperation in Divisible Good Auctions: An Experimental Examination*
}

\author{
Orly Sade \\ Jerusalem School of Business \\ Hebrew University of Jerusalem \\ Charles Schnitzlein \\ College of Business \\ University of Central Florida \\ Jaime F. Zender \\ Leeds School of Business \\ University of Colorado at Boulder
}

First Draft: 6/6/02

This Draft: 8/05/04

\footnotetext{
*We thank Emmanuel Morales-Camargo and Yelena Larkin for their excellent research assistance. We also thank Yigal Arnon, the CEO and the employees of Bank Leumi of Israel and the management and the employees of the Monetary Department of the Bank of Israel for all their help in gathering the data from the professional participants. We have benefited from comments by Haim Levy, Frans van Winden, Vernon Smith, Atanu Sinha, Jill Zender, Nathalie Moyen, Brian Kluger, Glenn Harrison, Maureen O’Hara (the editor), an anonymous referee, and seminar participants at the University of Central Florida, IDC, the Hebrew University of Jerusalem, the Technion, Tel-Aviv University, the Norwegian School of Economics and Business Administration, Toulouse Business School, Aston Business School, Erasmus University, the University of South Florida, the Atlanta Federal Reserve, the 1999 IFREE/Economic Science Laboratory Summer Visiting Graduate Workshop, the 2002 ESA meetings at Harvard, the 2003 Southern Finance Association Meetings, and the 2003 Auction and Market Design Conference in Milan. Sade thanks the Krueger Center for Finance at the Hebrew University of Jerusalem for partial financial support.
} 


\title{
Competition and Cooperation in Divisible Good Auctions: An Experimental Examination
}

\begin{abstract}
An experimental approach is used to examine the performance of three different multi-unit auction designs: discriminatory, uniform-price with fixed supply, and uniformprice with endogenous supply. We find that the strategies of the individual bidders and the aggregate demand curves are inconsistent with theoretically identified equilibrium strategies. The discriminatory auction is found to be more susceptible to collusion than are the uniform-price auctions, and so contrary to theoretical predictions and previous experimental results the discriminatory auction provides the lowest average revenue. Consistent with theoretical predictions, bidder demands are more elastic with reducible supply or discriminatory pricing than in the uniform-price auction with fixed supply. Despite a lack of a priori differences across bidders, the discriminatory auction results in significantly more symmetric allocations.
\end{abstract}




\section{Introduction}

Many countries use auctions to sell their Treasury securities. While the institutional details of the auctions differ in a variety of subtle ways across countries, most use a variant of either a uniform or a discriminatory pricing rule. In recent years there are examples of countries switching from the discriminatory to the uniform-price format (e.g., the United States) and examples of countries making the reverse change (e.g., France), indicating that the choice between these mechanisms remains an unsettled issue. ${ }^{1}$

We use the experimental economics laboratory to examine some of the tradeoffs implicit in the choice over auction designs. Our experiment compares the two most common auctions (discriminatory and uniform-price) in a multi-unit, common value setting. The auctions are evaluated along the dimensions of average revenue, symmetry of allocations across bidders, and their susceptibility to collusion. We also study the impact on auction performance of an aspect of auction design that has only recently received theoretical attention: allowing the seller to endogenously select the quantity sold in a uniform-price auction after observing the bids.

Despite theoretical progress in analyzing multi-unit auctions, definitive comparisons of the expected revenue and other measures of the performance of alternative auction formats are difficult to accomplish. The strategy space in these games is large and there often exist multiple equilibria. In addition, typical features of Treasury auctions make it appropriate to model them as a repeated game. Consequently, the propensity of bidders to engage in tacit collusion or outright cooperation across the

\footnotetext{
${ }^{1}$ See Bartolini and Cottarelli (1997) for cross-country evidence on the design of Treasury auctions.
} 
different mechanisms is a primary aspect of auction performance. ${ }^{2}$ All of the foregoing issues make the experimental laboratory a natural direction in which to turn.

Much of the debate on Treasury auction design focuses on the revenue implications of the alternate pricing rules. Milton Friedman (1960) and others advocated a switch by the U.S. Treasury from its discriminatory format to a uniform-price auction. Friedman argued that, bidders being awarded allocations at prices greater than the stopout price, (1) had the effect of driving out unsophisticated bidders, (2) increased incentives for bid shading in response to the winner's curse, and (3) increased the incentive for participating bidders to collude.

The theory of multi-unit auctions has identified an added dimension to the problem of Treasury auction design. This work shows that there exist non-cooperative equilibria under the uniform-price format that support outcomes in which the auction's stop-out price is much lower than the value of the asset offered for sale. Since the discriminatory auction does not allow such equilibria, the question becomes whether the more severe winner's curse and potential susceptibility to collusion of the discriminatory format are less costly to the auctioneer than the "collusive-looking” outcomes that are possible with uniform-pricing. ${ }^{3}$

Recent theoretical work also examines the implications of allowing the seller the option of reducing the quantity sold after observing the bids in uniform-price auctions. Back and Zender (2001) show that having the seller retain this right severely restricts the

\footnotetext{
${ }^{2}$ Klemperer (2002) argues that most issues in the auction literature are of second-order importance for practical auction design. Discouraging collusive, entry-deterring, and predatory behavior are the key concerns he identifies.

${ }^{3}$ For example, see Wilson (1979), Back and Zender (1993), Ausubel and Cramton (1996) or Wang and Zender (2002) for theoretical results on strategic bidding in multi-unit auctions.
} 
strategic advantage provided to bidders in a uniform-price auction. The uniform-price auction with reducible supply may therefore enjoy the relative advantages of uniformpricing without its potential costs.

To explore these arguments, we ask whether the use of discriminatory pricing or reducible supply is a more effective way to eliminate the bidders' strategic advantage in multi-unit auctions. We examine this question by comparing actual bidding behavior with equilibrium bidding strategies. We also ask whether the discriminatory auction is more susceptible to collusion than the uniform-price auction. Since Treasury auctions commonly involve a small number of bidders that interact periodically (characteristics that facilitate cooperative behavior), the experimental design is intended to study relative performance in a setting where both cooperation and competition are plausible outcomes.

Our experimental design compares the performance of three distinct auctions: uniform-price; discriminatory (both multi-unit auctions in which the quantity offered at auction is fixed and completely price inelastic, labeled uniform-fixed and discriminatory in the sequel); and uniform-price with endogenous supply (in which the seller may reduce the quantity sold after observing demand, labeled uniform-reducible). We use a common values setting in which bidders understand that they are playing a repeated game and participate in at least fourteen auctions in a session. Five bidders participate in each session (a large body of experimental evidence indicates four agents are sufficient in many situations to imply a competitive outcome). Subjects are allowed to engage in nonbinding communication both before and during the conduct of the auctions; however, absolute privacy is maintained with respect to their actions. We thus study relative 
mechanism performance in a setting for which the competitive outcome is expected but barriers to cooperative behavior are low. ${ }^{4}$

Our major results are as follows. Bidding strategies under all three auction mechanisms are generally inconsistent with the equilibrium strategies identified by theory. This is true for both individual demand curves and aggregate demand curves. As predicted by theory, the uniform-reducible auctions lead on average to higher revenue than the uniform-fixed auctions, although the difference is not statistically significant. We also find the discriminatory auction to be the most susceptible to collusion. Contrary to the theoretical prediction, this results in lower revenue than the uniform-price auction.

In many markets the seller is concerned not only with the auction's revenue but also with the effect of the auction on secondary market trading. Treasuries recognize that broader participation and more symmetric allocations in the primary market can promote a higher quality secondary market. ${ }^{5}$ Despite the lack of a priori differences across bidders, we find allocations are most symmetric in the discriminatory auction followed by the uniform-fixed auction, with the uniform-reducible auction having the least symmetric allocations.

Most of the experimental economics literature investigating auctions has focused on single-unit auctions. An extensive review of this literature is provided in Kagel (1995). A relatively small number of experimental papers have addressed auction design where multiple units are for sale. Smith (1967) compares uniform-price and discriminatory auctions in a common value setting arbitrarily restricting the maximum

\footnotetext{
${ }^{4}$ See Fehr and Fischbacker (2003) for a review of the experimental literature reporting cooperative behavior when equilibrium behavior is competitive.

${ }^{5}$ See, for example, Malvey, Archibald, and Flynn (1995), Malvey and Archibald (1998), and Jegadeesh (1993).
} 
quantity each bidder may bid for to two units. He finds that the variance of bids is greater under the uniform-price auction, but does not find significant differences with respect to revenue. Miller and Plott (1985) compare uniform-price and discriminatory auctions in a private-value setting where the maximum demand is restricted to two units and also find inconclusive evidence concerning revenue. Cox, Smith, and Walker (1985) compare multi-unit discriminatory and uniform-price auctions with unit demand. Despite the presence of ten bidders in each session and no communication, they find evidence of tacit collusion in sessions with experienced subjects.

Our paper is most closely related to Goswami, Noe, and Rebello (1996) (GNR). GNR investigate the role of communication in the adoption of equilibrium strategies in uniform-price and discriminatory auctions. Using eleven bidders per session with fixed supply under both formats, they find that with nonbinding communication, revenue is higher in the discriminatory auctions and that the uniform-price auctions are subject to collusion. However, the small number of experimental sessions used by GNR precludes strong conclusions being drawn from their investigation.

This study is distinct from GNR's examination in that we find a reverse ordering for revenue in the uniform-price and discriminatory auctions, and provide an experimental examination of the implications of endogenous supply. In addition, we use an experimental design more conducive to coordination than the GNR setting. Finally, we use both students and finance industry professionals as subjects in order to examine the potentially important role of subject sophistication in market outcomes.

This paper is organized as follows. Section 2 describes the theoretical foundations of our experiment. In section 3 we discuss the experimental design, and 
present our results in section 4 . Section 5 contains concluding remarks. The appendix contains the instructions to the participants.

\section{Theory}

In multi-unit auctions bidders may submit multiple price quantity pairs (demand schedules) as bids. Bids are aggregated and the highest price at which aggregate demand equals supply is termed the stop-out price. Winning bids are those submitted at or above the stop-out price. In uniform-price auctions the stop-out price is paid for all winning bids while in discriminatory auctions the price paid for winning bids is the bid price.

The strategic advantage enjoyed by the bidders in a uniform-price auction may be explained as follows. In a uniform-price auction bidders are able to submit "steep" (inelastic) demand schedules that result in their sharing the total quantity at a price far below the value of the good. Such an outcome can exist as an equilibrium outcome if the bid schedules are "steep enough.” The pricing rule in a uniform-price auction implies that any deviations from the equilibrium bids that allow a bidder to capture an amount greater than his/her equilibrium allocation are unprofitable. Capturing additional quantity (which is desirable because price is below value) requires bidder $i$ to "out bid” other bidders for their equilibrium allocations. The steepness of the bid functions implies that the price paid for all units rises significantly for each additional unit captured in such a deviation. In essence, the steep demands submitted by the other bidders make marginal cost higher than price for additional units and so act to inhibit price competition among the bidders in equilibrium. Further, given the uniform-price format, the high inframarginal bids that support the equilibrium are costless to the bidders. In 
equilibrium, the steeper are the individual demand curves, the lower is the stop-out price that may be sustained (see Theorem 1 in Back and Zender (1993)).

In a discriminatory auction, bids submitted above the equilibrium stop-out price are not "costless" as they are in the uniform-price format. All winning bids are filled at the bid price. As compared to the uniform-price auction, bidders in a discriminatory auction therefore tend to submit "flatter" bid functions. This induces more price competition among bidders in a discriminatory auction. In other words, the discriminatory pricing rule implies that, regardless of the "shape" of the bid schedules submitted by the other bidders, the marginal cost of an additional unit always equals price. Therefore, in a "frictionless" auction game the competitive outcome obtains in any equilibrium (see Theorem 3 in Back and Zender (1993)).

While the use of discriminatory pricing eliminates the strategic advantage given to bidders in a uniform-price auction, it suffers more from the "winner's curse"6 if the environment includes private information and affiliated valuations. It is therefore important to evaluate the extent to which the potential pitfalls of the standard uniformprice framework may be "cured." A common feature of treasury auctions is that the seller retains the right to change the quantity sold after observing the bids. Back and Zender (2001) evaluate this feature of uniform-price auctions and show that it eliminates "most" of the equilibrium outcomes for which the equilibrium stop-out price is below the value of the good. A seller, acting to maximize revenue, will find it optimal to restrict supply when the aggregate demand curve is “steep enough” that the reduction in quantity

\footnotetext{
${ }^{6}$ Because, in an auction, allocations are made to the highest bids, bidders lower or shade their bids relative to their estimates of value so that winning is not a signal their estimate was too optimistic. This response to what is called the "winner's curse” lowers the seller's expected revenue. Bid shading in response to the winner's curse is stronger the more directly a bidder's own bids affect the price paid for units won.
} 
sold is more than offset by the resulting increase in the stop-out price. Bidders are rendered strictly worse off by any ex post quantity reduction, so this feature of the auction places a limit on how steep the individual bid functions may be in any equilibrium. Because steeper demands are associated with lower sustainable stop-out prices, limiting the slope of the equilibrium bid functions effectively restricts the extent to which bidders may exercise their strategic advantage (see Theorem 2 in Back and Zender (2001)).

The experiment in this paper examines the mechanism design results discussed above. We use an auction game in which $\mathrm{N}=5$ bidders compete for $\mathrm{Q}^{*}=26$ units of a good labeled a widget. In order to abstract from concerns over the winner's curse and concentrate on the strategic aspects of the auction, we ensure that it is common knowledge among the bidders that the after-market value of the widget is 20. Each bidder submits quantity orders at 4 distinct prices as bids in each auction. Each quantity order must be for a weakly positive integer number of units (the aggregate quantity demanded by a bidder is restricted to be less than or equal to $\mathrm{Q}^{*}$ ) and the allowable prices are $\{17,18,19,20\}$. A quantity order is an offer to purchase the specified number of units at a price equal to or below the price at which that order is submitted.

Beginning with quantities submitted at a price of 20, the seller aggregates all bid schedules to create a downward sloping aggregate demand curve. In the auctions with fixed supply the stop-out price is established as the highest price at which supply equals or exceeds the fixed supply. Winning bids are those submitted at or above the stop-out price. All quantities demanded at prices strictly above the stop-out price are filled. For orders submitted at the resulting stop-out price bidders may be rationed. 
Rationing is done in a pro-rata fashion. Specifically, the aggregate quantity demanded at the stop-out price is computed. The quantity demanded at the stop-out price by a given bidder is divided by the aggregate quantity demanded at the stop-out price to determine the proportion of the rationed quantity that bidder is to receive. The rationed quantity is determined by subtracting the aggregate quantity demanded at all prices strictly above the stop-out price from the final supply. The case of a uniform-price auction with reducible supply will be described more completely below.

The Uniform-Price Auction with Fixed Supply

Because there is no a priori reason to assume any one bidder is different from any other, we concentrate our discussion on the symmetric equilibria of the auction games we examine (asymmetric equilibria are discussed below). For the case of the uniform-price auction with fixed supply, a simple application of the analysis in Back and Zender (1993) indicates that there exist 4 possible equilibrium stop-out prices; each of the allowable bid prices can be supported as the equilibrium stop-out price by an appropriate set of equilibrium bid functions. The analysis of the equilibria in the discrete framework is an application of proofs in Back and Zender (1993) and closely follows GNR (1996).

The bidders can reach a competitive outcome in a symmetric Nash equilibrium of the uniform-price auction if all bidders submit bids for at least 7 units at a price of 20. As discussed above, to support equilibria with stop-out prices less than the competitive level the equilibrium bid functions must be increasingly steep as the target stop-out price is reduced. The result can be summarized as follows:

Proposition 1: There exist symmetric Nash equilibria of the uniform-price auction with fixed supply that result in stop-out prices at any of the four possible price levels. (i) If all bidders submit demands for 3, 4, or 5 units at a price of 20, demand no units at 18, 21 units at a price of 17, and demand the balance of the 26 total units at 19, the equilibrium stop-out price will be 17. (ii) A stop-out price of 18 can be supported if all bidders 
submit demand curves with a total demand of 5 units at prices of 20 and 19, with at least 4 units demanded at 20, and 21 units demanded at 18. (iii) A stop-out price of 19 can be obtained in equilibrium if all bidders submit demands for 5 units at a price of 20 and demand for 21 units at 19. (iv) The competitive outcome is an equilibrium if all bidders submit demands for 26 units at a price of 20. In all of the symmetric equilibria each bidder will receive 5 and $1 / 5^{\text {th }}$ units.

A difficulty in working with the uniform-price auction is the multiplicity of Nash equilibria. Only the Pareto dominant equilibria, those with stop-out prices of 17 , are coalition proof (see Bernheim, Peleg, and Whinston (1987) and the discussion in Goswami, Noe, and Rebello (1996)). Furthermore, each bidder obtains an added payoff of Fr. 5.2 in these equilibria relative to the equilibria in which the stop-out price is 18. We will, therefore, focus on these equilibria in our analysis.

\section{Discriminatory Auctions}

Theorem 3 in Back and Zender (1993) indicates that in a discriminatory auction, when the value of the good is common knowledge, the good is perfectly divisible, and the price grid is continuous, the competitive outcome is obtained for the seller in any Nash equilibrium. The common knowledge aspect is important in eliminating issues related to the winner's curse, and continuity is necessary so that price competition can be as effective as possible. In the auction presented here there are actually two equilibria. The first is the competitive equilibrium in which all bidders submit bids of 26 units at a price of 20. This results in the bidders receiving none of the surplus from the auction and is an equilibrium in weakly dominated strategies since it is not possible for a positive payoff to result from bids at a price of 20. The second equilibrium has all bidders bidding for 26 units of the good at a price of 19. While this is not the competitive outcome, this is an equilibrium of the discriminatory auction because the value of the good is known to be equal to the next available bid price. A bidder who bids for any positive quantity at a 
price of 20 will always receive a zero payoff on those units. Essentially, discreteness in the allowable price levels acts as a friction that limits the extent of price competition.

Proposition 2: The only Nash equilibrium in undominated strategies in a discriminatory auction has all bidders submitting demands for 26 units at a price of 19.

If any bidder plays this equilibrium strategy then the others will find the same strategy optimal. Bidding for a positive quantity at a price other than 19 will have a zero payoff if each bidder expects at least one other bidder to play the equilibrium strategy. Relative to the uniform price auction with fixed supply the equilibrium demands in the discriminatory auction tend to be "flatter" and contain less of a discount implying higher expected revenue for the seller.

\section{Uniform-Price Auction with Reducible Supply}

With reducible supply, the seller announces a target supply of $\mathrm{Q}^{*}$ at the beginning of the auction but retains the right to reduce the actual quantity supplied after observing the submitted bids. The seller is assumed to choose the actual supply to maximize profit. For purposes of illustration, suppose the seller faces a cost for deviating from the announced supply and model this cost as $\mathrm{C}(\mathrm{Q})=\mathrm{k}\left(\mathrm{Q}^{*}-\mathrm{Q}\right)$, for some positive parameter k. After observing the submitted bid functions the seller aggregates the bids and then chooses $\mathrm{Q} \leq \mathrm{Q}^{*}$ to maximize his net profit.

When the seller retains the right to reduce supply, the set of equilibrium outcomes is reduced as compared to the set of equilibria in the uniform-price auction with fixed supply. Because the seller is able to reduce the supply, bidders have an incentive to submit as "flat" a bid function as possible to support a given stop-out price as an equilibrium. The extent to which the set of equilibria is reduced depends upon the parameter, $k$, in the seller's cost function. For this discussion we examine two values for 
the cost parameter: 0 and 8 . With a cost parameter of zero, the only equilibrium of a uniform-price auction with reducible supply is the competitive equilibrium. The willingness of the seller to deviate from the announced supply induces the bidders to submit bid functions so flat that only a stop-out price of 20 can be sustained in equilibrium. With a cost parameter of 8 the seller is reluctant to reduce supply ex post; consequently, only a stop-out price of 17 cannot be supported in equilibrium.

Proposition 3: In a uniform-price auction with reducible supply: (i) If the seller faces no cost of deviating from the target quantity $Q^{*}$ the only equilibrium is the competitive outcome. (ii) If the seller has a cost parameter $k=8$ for deviations from the target quantity then the prices 18, 19, and 20 can be sustained in an equilibrium. In order to sustain 18 as an equilibrium stop-out price bidders must submit demands for 4 units at a price of 20, 1 unit at 19 and 21 units at 18 (i.e., submit the "flattest" of the equilibrium bid functions presented in Proposition 1).

In our experiments we use a cost parameter of 0 in order to provide the maximum impact for the seller's right to choose supply ex post and the existence of a unique equilibrium. As in the case of the discriminatory auction, relative to the uniform-price auction with fixed supply, the increased price competition motivated by reducible supply implies the equilibrium bid schedules are more elastic and contain less of a discount.

A notable aspect of these strategies is that the bids for the first 6 units enforce the equilibrium stop-out price. For example, consider the equilibrium in the uniform-price auction with fixed supply in which bidders submit demands for 5 units at a price of 20 and 21 units at a price of 18. These demands result in a stop-out price of 18 and a symmetric allocation of the good. The bid for 5 units at a price of 20 allows the equilibrium stop-out price to be lower than value and the first unit demanded at 18 establishes the level of the stop-out price. The other 20 units demanded at the price of 18 are simply there to ensure each bidder gets the largest possible share of the " $26^{\text {th }}$ unit." 
The use of the Nash equilibrium concept lies behind the shape of the "tail" of the equilibrium strategy. If bidders believe there is a significant chance others may deviate from the equilibrium strategy they may use their bids for the final 20 units differently than is described by the equilibrium strategies. It will therefore be interesting not only to compare the actual total demand curves with the equilibrium strategies, but also, to compare the demands placed for the first 6 units with the equilibrium strategies.

In summary, the testable predictions are:

1. Bidders' demand curves should be flatter and include less of a discount in the discriminatory auction as compared to those in the uniform-fixed auction.

2. Bidders' demand curves should be flatter and include less of a discount in the uniform-reducible auction as compared to those in the uniform-fixed auction.

3. The seller's average revenue should be highest in the uniform-reducible auction followed by the discriminatory auction and lowest for the uniform-fixed auction.

4. Allocations of the good in the auctions should be symmetric without significant differences across the different mechanisms.

5. The multiplicity of equilibria in the uniform-fixed mechanism allows for more variation in revenue across auctions than do the other mechanisms.

\section{Experimental Design}

\subsection{Auction Rules}

In each auction, subjects submitted bid schedules at computer terminals for units of a good that we called widgets. All monetary values were denominated in an experimental currency referred to as Francs (Fr.). The resale value of each widget was Fr. 20 for all 
subjects, and this was common knowledge at the start of bidding. A bidder's payoff in an auction was calculated as the sum, over all units allocated to that bidder, of the differences between the resale value of each unit allocated and the price paid for that unit. The details of pricing, allocations, and quantities supplied in the different auctions are as described above.

\subsection{Experimental Methodology}

Each experimental session consisted of 5 subjects and each cohort of 5 subjects was involved in a single experimental treatment. We employed both students and finance industry professionals as subjects. The students were senior undergraduate, MBA, and MIS students. All had had at least one course in finance, and courses in statistics and economics. There were two types of professional subjects. The first group consisted of employees of the monetary department of the Bank of Israel, which is responsible for the design and routine conduct of the notes auctions and for the routine conduct of the bond auctions for the Israeli Treasury. The second consisted of three cohorts of mutual fund and pension fund managers at a leading investment bank in Israel. All members of this second group had had experience with financial asset auctions.

Table 1 lists the information pertaining to each experimental session. Five repetitions of the uniform-fixed and the discriminatory treatments and four repetitions of the uniform-reducible were conducted with students. Two repetitions of each treatment were conducted with professionals. There were at least 14 auctions conducted in each experimental session with the exact number chosen randomly. In order to control for experience effects, we analyze only the first 14 auctions in each experimental session.

At the start of each experimental session, subjects were seated in a conference room and given written instructions. The instructions explained the auction rules, the basis on 
which cash payments would be made, and included images that introduced the subjects to the software used to conduct the experiment. The instructions were read aloud, and subjects were then given the opportunity to ask clarifying questions. The student subjects were then given a quiz to ensure their understanding of the bidding and allocation rules. (A copy of the written instructions, sample computer screens, and the quiz are included in the appendix.)

Subjects were allowed to discuss strategies and outcomes with each other before, during, and after each auction. The layout of the computer lab, however, prevented each subject from seeing the screen of any other subject, and subjects were informed that this would be counter to the auction rules. Therefore, while communication was open, actual bidding behavior remained private knowledge. After the final auction in each session each subject's screen automatically reverted to a blank screen (to maintain the privacy of bidding behavior as subjects left the lab) and student subjects were paid individually in a side room. The exchange rate between Fr and \$US (the currency in which subjects were paid) was \$US $=10$ Fr. Payments to student subjects averaged \$20. (Regulations precluded cash payments to most of the professional subjects, so we rewarded them with prizes bearing the logos of the researchers' sponsoring universities.)

The auctions were conducted with custom designed software. In addition to allowing the entry of bids, the software graphed individual demand curves in real time as each subject initiated the bid submission process. The aggregate demand schedule, stopout price, and allocations for each round were calculated by the software at the completion of each auction. After each round each bidder was provided with information on the number of total units demanded at each price. In addition, the interface provided historical information pertaining to each subject's previously submitted demand functions 
matched with their allocations, profit, and percentage of available supply received for each completed auction. Each experimental session lasted approximately 45 minutes.

\section{Experimental Results}

We assess the experimental outcomes along the following dimensions: bidding strategies, clearing prices, seller’s revenue, and the symmetry of the allocations.

\subsection{Bidding Basics}

Prior to comparing the actual bids to the equilibrium strategies, there are some basic aspects of bidding in the auction games, identified by the propositions above, that are interesting to examine. Proposition 2 notes that bidding in the discriminatory auction for any quantity at a price of 20 is a weakly dominated strategy in a one-shot game. Given the simplicity of establishing that a bid at 20 is a dominated bid we expected to see little or no bidding in the 98 discriminatory auctions at the price of 20. Examination of the data shows that only in 3 of the 98 discriminatory auctions did any bidder submit orders at a price of 20. It is also true that the bids all came from the same bidder and do not appear to be part of a punishment/retaliation strategy. Thus only 1 of the 35 bidders that participated in the discriminatory auctions submitted a bid that was weakly dominated in this way. None of the 10 professionals who participated in discriminatory auctions submitted bids at a price of 20 .

The theoretical results also identify bidding for fewer than 26 units in any auction as a weakly dominated strategy. Examination of the data shows that this occurred in only 29 of the $280(10.5 \%)$ auctions. Interestingly, this strategy occurred more often in the uniform-reducible auctions (where in $15.5 \%$ of the auctions bidders submitted demands 
for fewer than 26 units) than in the uniform-fixed and the discriminatory auctions (8.2\% of these auctions). ${ }^{7}$ The exact reason for this difference is unclear but may be related to expectations of a supply reduction. The occurrence of this strategy tended to be isolated in the sense that in only one of the 29 auctions with aggregate demand less than 130 units did more than one bidder bid for less than 26 units. $21 \%$ of bidders played this weakly dominated strategy in 12 of the 20 sessions. $40 \%$ of the professionals played strategies that were weakly dominated in this way while less than $13 \%$ of the students did. ${ }^{8}$

A final notable aspect of the bidding is the extent of collusion that occurred in the auctions across the different mechanisms. Collusion in the auctions could take on many forms and so it is difficult to completely examine this issue. However, one collusive scheme which we label "perfect collusion" is easily identifiable. If all 5 bidders submit demands for 26 units at a price of 17 in any auction we call this a perfectly collusive outcome. Regardless of the pricing rule, perfect collusion results in all units being allocated evenly across the 5 bidders at the lowest possible price. It is clearly collusive in the sense that for any bidder, if all other bidders are expected to play these strategies, there exist easily identifiable strategies that will capture a much greater allocation with either an increase in price of one Franc (necessary in the discriminatory auctions) or no increase in price (possible in uniform-price auctions).

Relative to the competitive outcome (equilibrium in the uniform-reducible auctions) there are strong incentives for subjects to collude. The competitive outcome results in zero profits for all bidders. The profit per bidder from perfectly collusive play

\footnotetext{
${ }^{7}$ Using each auction as an independent observation this difference is not significant at conventional levels $(\mathrm{p}=0.16)$ using the Fisher exact test.

${ }^{8}$ This difference is significant $(\mathrm{p}<0.01)$ treating each subject as an independent observation.
} 
is Fr. 15.6 in each auction. Over (a minimum of) 14 auctions the added profit per bidder is Fr. 218.40 (or \$21.84). However, as just noted, the added payoff for unilateral deviation from the perfectly collusive strategy is Fr. 36.4 in a single discriminatory auction or Fr. 59.43 in a single uniform-price auction.

Consistent with the arguments developed in Friedman (1960), the discriminatory auctions were more susceptible to perfect collusion than were the uniform-price auctions. Of the 7 sessions of discriminatory auctions, 3 sessions saw the perfectly collusive outcome in all 14 auctions (labeled perfectly collusive sessions in the sequel). Of the 13 sessions using a uniform-price format only 4 were perfectly collusive sessions. Using the Fischer exact test $(\mathrm{p}<=0.01)$ or the t-test $(\mathrm{p}<0.01)$ the discriminatory auctions are significantly more collusive than the auctions using the uniform-price format when each auction is treated as an independent observation. A lack of independence across auctions within a session is likely to mean these significance levels are overstated. The most conservative control for this problem of "cohort effects," using each session as an observation (the number of observations is 6 or 7), implies the difference is insignificant.

Two of the discriminatory sessions resulted in the perfectly collusive outcome in the final 4 auctions of the session. The remaining 2 discriminatory sessions are the only discriminatory sessions that did not result in perfectly collusive outcomes for a significant proportion of the auctions. These remaining discriminatory sessions converged to the equilibrium outcome. Of the sessions using the uniform-price format that were not perfectly collusive, only one saw the perfectly collusive outcome in the final auctions. This session, however, also saw perfectly collusive strategies used in the first two

\footnotetext{
${ }^{9}$ Cohort effects arise when results from an experimental session (a set of interactions with a single group of subjects) are affected by characteristics of the subjects themselves independently of the mechanism.
} 
auctions. Defining convergence to the perfectly collusive outcome as sessions that do not start at the collusive outcome but realize that outcome in the final auctions ${ }^{10}$ there are significant differences between the discriminatory and the uniform-price auctions. For the discriminatory auction 2 of 4 sessions converged to the perfectly collusive outcome while in the uniform-price format, of the 8 sessions that did not begin with a perfectly collusive outcome, none converged to the collusive outcome. ${ }^{11}$ Finally, note that only the discriminatory format saw a perfectly collusive session with the professional subjects.

Interestingly, one session of the uniform-reducible auction resulted in the perfectly collusive outcome in the first auction. In the second auction of this session, however, one bidder defected, and submitted a demand for all 26 units at a price of 18 breaking the coalition. In the remaining 12 auctions for this session the resulting stop-out price was either 19 or 20 (6 at each price) indicating an aggressive response to defection.

\subsection{Bidding Strategies}

The complexity of the strategy space available to bidders in multi-unit auctions makes the comparison of the actual bid schedules submitted by the participants to the theoretical equilibrium demands somewhat difficult. Keloharju, Nyborg and Rydqvist (2002) use a methodology that compares the moments of the distribution of the individual bids on a given bid schedule to the moments of the theoretical equilibrium schedules. We adopt their methodology to make comparisons between the actual individual demand schedules and each of the possible equilibria for a particular setting.

\footnotetext{
${ }^{10}$ This definition is used because the outcomes of the first rounds of each session are likely to be more reflective of characteristics of the cohort than the mechanism. The change in behavior of cohorts that do not begin playing a collusive strategy will be more reflective of the mechanism. Note also that in all sessions that converged to the collusive outcome this outcome was realized for at least the final 4 auctions.

${ }^{11}$ This is a statistically significant difference with the Fischer exact test and the t-test providing p-values of 0.04 and 0.03 respectively.
} 
Before examining the actual demands we investigate whether the subjects actually submit demand schedules rather than a single price/quantity combination. Figure 1 shows that in many auctions (59\% in the uniform-fixed auctions, 58\% in the uniformreducible auctions, and 36\% in the discriminatory auctions) at least one bidder submitted multiple price/quantity combinations. This is consistent with the empirical finding in Nyborg, Bindseil and Strebulaev (2002) in their study of repo auctions. It is, however, very different from the theoretical predictions. In the coalition proof equilibria of the uniform-fixed auction, theory predicts that all subjects will submit multiple price/quantity pairs as bids. Figure 1 also shows that only $9 \%$ of uniform-fixed auctions saw all 5 subjects submit multiple price/quantity pairs as bids. In both the uniform-reducible and discriminatory mechanisms, theory predicts that all subjects will submit a single pricequantity combination as a bid. The discriminatory auctions come closest to this prediction; 64\% of these auctions result in all bidders submitting flat demands.

The first moment of the demand curves we consider is the discount. The discount is measured as the difference between the secondary market price and the quantity weighted average price, $\bar{p}$, of a bidder's demand schedule. Let $\mathrm{q}_{\mathrm{i}}$ denote the quantity on a given demand curve demanded at a price $i$, where $i \in\{17,18,19,20\}$ and let $q_{T}=\sum_{i=17}^{20} q_{i}$, then $\bar{p}=\frac{1}{q_{T}}\left(20 \times q_{20}+19 \times q_{19}+18 \times q_{18}+17 \times q_{17}\right)$.

In our case, the secondary market price is known with certainty and equal in all the experiments so the discount and the quantity weighted average price contain the same information. The standard deviation of a given demand curve is calculated as: 


$$
\sigma=\left[\frac{1}{q_{T}}\left(q_{20}(20-\bar{p})^{2}+q_{19}(19-\bar{p})^{2}+q_{18}(18-\bar{p})^{2}+q_{17}(17-\bar{p})^{2}\right)\right]^{1 / 2}
$$

The skewness and kurtosis of a demand curve are calculated as:

$$
s^{3}=\left[\frac{1}{q_{T} \times \sigma^{3}}\left(q_{20}(20-\bar{p})^{3}+q_{19}(19-\bar{p})^{3}+q_{18}(18-\bar{p})^{3}+q_{17}(17-\bar{p})^{3}\right)\right]
$$

and

$$
k^{4}=\left[\frac{1}{q_{T} \times \sigma^{4}}\left(q_{20}(20-\bar{p})^{4}+q_{19}(19-\bar{p})^{4}+q_{18}(18-\bar{p})^{4}+q_{17}(17-\bar{p})^{4}\right)\right] .
$$

Table 2-A compares the moments of the equilibrium individual demand curve to the average individual demand curve submitted in each type of auction. To examine the question of whether "in aggregate rather than individually" the subjects were playing equilibrium strategies, Table 2-B compares the moments of the equilibrium aggregate demand curves to the average aggregate demand curves submitted in each type of auction. With either method, the results indicate that the actual bidding strategies of the subjects differ significantly from the theoretical predictions for all three mechanisms. ${ }^{12}$

Tables 2-A and 2-B, and Figure 2, illustrate that the demands submitted by the subjects differed from the equilibrium demands in particular ways. In the discriminatory auctions, bidders on average submit steeper bid schedules and lower bids (bids with a greater discount) than predicted by the theory. The steepness arises because the equilibrium demand is completely flat while the actual demands are not. The greater discount arises from collusion. The same differences occur in the uniform-reducible

\footnotetext{
${ }^{12}$ In the uniform-fixed mechanism there exists a family of asymmetric equilibria in which the aggregate demand curve of each asymmetric equilibrium is equivalent to the aggregate demand curve of a symmetric equilibrium. Rejection of the symmetric equilibria for the uniform-fixed auctions based on the aggregate demands (Table 2B) also constitutes a rejection of these asymmetric equilibria.
} 
auctions. The measures of the discount and dispersion of the actual demands are both significantly greater than the measures suggested by the theory. However, in the uniform-fixed auctions the submitted demands (Figure 2) are flatter and include a smaller discount. Tables 2-A and 2-B show that the measures of discount and dispersion are significantly smaller than those implied by the theory. This indicates that bidders did not recognize the strategic advantage provided by the ability to submit demand curves in the uniform-price auction, engaging instead in naïvely competitive behavior. ${ }^{13}$

Figure 2 suggests that in many cases the differences from theoretical equilibrium may have been driven by the "tail" of the individual demand curves, i.e., that part of the individual's demand curve (for cumulative quantities greater than 6) for which there is relatively little chance of an allocation. To investigate the conjecture that the bidders were in fact bidding for the "first 6 units" with equilibrium strategies, we repeated the moment calculations using only these first units demanded by each bidder. Table 2-C indicates that on average the aggregation of the individual demands submitted for the "first 6 units" are significantly different from the theoretical prediction for this curve. ${ }^{14}$

As compared to the uniform-fixed mechanism, theory predicts that the use of discriminatory pricing or reducible supply will "raise" and "flatten" the individual demands. Figure 3 shows that, as predicted, reducible supply results in lower discounts and flatter demands than were submitted in the uniform-price auctions with fixed supply. However, the differences in the discounts and the standard deviations are not statistically

\footnotetext{
${ }^{13}$ This result is consistent with the findings of GNR. The result does not change if we restrict attention to sessions of the uniform-fixed auction using professional participants.

${ }^{14}$ As a further robustness check, we examined the average of the individual demands restricting attention to the first 6 units demanded and found similar results. We also eliminated from the sample the perfectly collusive sessions. The same qualitative results were obtained.
} 
significant. Discriminatory pricing also results in flatter demand curves; ${ }^{15}$ however, the discounts are greater rather than lower. The larger discount appears again to be the result of the greater incidence of perfect collusion in the discriminatory auctions.

Given that subjects do not play Nash strategies, an interesting question to ask is: Were subjects leaving significant amounts of money on the table by not adopting the equilibrium strategies? We can examine this question to a limited extent by calculating the average change in an individual subject's payoff generated by a switch to the Nash strategy, taking the strategies of the other bidders as given. This calculation makes an implicit assumption concerning a bidder's beliefs about the play of the other bidders. It is also true that in a repeated game environment examining the average payoff change in this way will overstate any improvement as it does not take into account the response of the other subjects in later auctions. While we cannot control for the response to a change in strategies we can partially control for this problem by eliminating from the analysis the 7 perfectly collusive sessions and evaluating only the remaining 13 sessions. As noted above, the observed response to a deviation from perfect collusion is aggressive.

In the uniform-reducible auction the equilibrium strategy is competitive bidding; all subjects bid for the entire quantity at a price of Fr. 20. A change to this strategy will in many cases entail a loss in payoff. The average loss from Nash play per bidder would have been Fr. 3.72 (\$0.37) in each auction. In the uniform-fixed auctions the coalition proof equilibrium strategies result in a stop-out price of 17 and the payoffs are equivalent to those under perfect collusion. The average increase in payoff a bidder would have received from a change to the equilibrium strategy was Fr. 1.73 (\$0.17) per auction.

\footnotetext{
${ }^{15}$ The difference between the average standard deviations in the uniform-fixed and the discriminatory auctions is statistically significant $(\mathrm{p}=.045)$.
} 
In the discriminatory auction the increase in revenue that would have accrued, on average, to a bidder from changing to the equilibrium strategy was Fr. 6.05 (\$0.61). The reason subjects appear to be leaving relatively large amounts of money on the table in the discriminatory auction is due to the fact that while this calculation excludes the perfectly collusive sessions, the remaining sessions saw perfectly collusive strategies in a large number of their auctions. Unilateral deviation from the collusive strategy is very profitable for an individual bidder in a single auction but may not maximize expected total payoff. For the two discriminatory sessions did not converge to perfect collusion (rather converged to the equilibrium outcome), examination of the bidding strategies auction by auction shows it was deviation from earlier perfectly collusive outcomes by one or two bidders that resulted in competitive play toward the end of these sessions.

The evidence indicates that bidders' strategies were "close" to equilibrium in the sense that they were not losing much by not using the Nash strategies. This is clearly true in the uniform-price auctions. In the discriminatory auction the reported increase is likely to be more representative of a one time change in profit for a bidder in exchange for a large reduction in subsequent auctions.

\subsection{Clearing Prices and Revenue}

In this section we compare clearing prices and revenue across the three mechanisms. Mean clearing prices and revenue by session are reported in Table 1. Auction by auction results for each session are reported in Table 3. Panel A of Figure 5 examines how revenue changes with experience over the 14 auctions.

Across all auctions and all sessions, average revenue is highest under the uniformreducible mechanism with average revenue of Fr. 481.1 and an average stop-out price of 
Fr. 18.5. The second highest revenue is realized under the uniform-fixed mechanism, with average revenue of Fr. 477.6 and an average stop-out price of Fr. 18.4. The lowest revenue obtains under the discriminatory pricing rule. Here revenue averages Fr. 462.4, the stop-out price averages Fr. 17.5 and the average price paid is Fr. 17.8 (recall that in the discriminatory auctions winning bidders pay their bids so the stop-out price is the lower bound for the average price paid). With the exception of a single auction under the uniform-reducible mechanism, all 26 units were sold in every auction. The revenue ranking from the auctions $\left(\mathrm{REV}_{\mathrm{UR}}>\mathrm{REV}_{\mathrm{UF}}>\mathrm{REV}_{\mathrm{D}}\right)$ differs from the third major theoretical prediction listed in Section $2\left(\mathrm{REV}_{\mathrm{UR}}>\mathrm{REV}_{\mathrm{D}}>\mathrm{REV}_{\mathrm{UF}}\right)$.

Panel A of Figure 5 shows noticeable patterns in revenue as the subjects gain experience in a session. For each time series, the first point represents the average for all auctions under each mechanism, the second point is the average for auctions 2 through 14, and the third is the average for auctions 3 through 14 , and so on. Under the discriminatory mechanism, revenue declines monotonically as later periods are compared with the global average. Three sessions maintain the perfectly collusive outcome for all 14 auctions and two additional sessions converge to this outcome. The remaining two sessions converge to the unique Nash equilibrium (a stop-out price of $\$ 19$ with symmetric allocations). Under the uniform-fixed mechanism, revenue is lower in the second half of the sessions. However, none of the sessions that start away from the collusive outcome converge to it with experience. Under the uniform-reducible pricing rule, revenue is almost constant with experience. Again, no session that starts away from the collusive outcome converges to it. Importantly, the revenue ranking based on global 
averages is sharpened when we compare later periods where subjects have gained experience with the mechanism and in interacting with other cohort members.

In order to assess the statistical significance of revenue differences across the three mechanisms, we face the challenge of simultaneously controlling for experience effects (which Figure 5 suggests are mechanism specific) and cohort effects. Since panel data methods that simultaneously control for both are extremely unreliable in small samples, ${ }^{16}$ we first perform analysis that controls for experience effects, and then perform analysis on the level of the session in order to control for cohort effects.

In order to test for revenue differences while controlling for experience effects, we first averaged the clearing price of all seven (six in the reducible mechanism) sessions for each of the three mechanisms according to their sequence (1-14) to get an average sequence of revenue for each mechanism. We then compare the first auction's revenue under each mechanism, the second auction's revenue, and so on. (Although this procedure perfectly controls for experience effects, it does not control for the potential lack of independence between auctions within a session and therefore biases downward standard errors.) We employ both the non-parametric approximate randomization test and a standard matched-pairs t-test, with all test statistics reported for two-tailed tests.

The average revenue sequence under the uniform-reducible pricing rule is higher than under the uniform-fixed mechanism, with the difference significant at the $10 \%$ level for both the randomization test and the t-test ( $\mathrm{p}=0.10$ and $\mathrm{p}=0.10$ respectively). Average revenue under the discriminatory mechanism is significantly lower than either uniformprice mechanism $(\mathrm{p}<0.01)$ for both tests.

\footnotetext{
${ }^{16}$ See, for example, Beck and Katz (1995).
} 
Table 3 indicates that revenue is higher in the sessions employing professionals as subjects. Significantly, when we disaggregate the data by subject type, revenue is lowest under the discriminatory mechanism for both types.

The most conservative data analysis strategy controls for cohort effects by treating the mean revenue from each session as a single data point. However, this approach does not control for differential rates of change in revenue across mechanisms as subjects become experienced. In order to control for within-session experience effects, we analyze the last 4 auctions from each session, since these are the auctions most likely to represent equilibrium outcomes (Figure 5 supports the choice of the last 4 auctions as the cutoff point). We calculate the average revenue over the last 4 auctions of each session and use each average as a data point in the following (OLS) regression:

$$
\text { REVENUE }=b_{1}+b_{2} U F+b_{3} U R+b_{4} P R O F+e .
$$

UF is an indicator variable that takes on a value of 1 in uniform-fixed sessions and 0 otherwise. UR is an equivalent indicator variable for uniform-reducible supply sessions. PROF is an indicator variable that takes on the value of 1 for sessions with professionals as subjects, and 0 otherwise. The indicator for the discriminatory mechanism is suppressed; the mean for the discriminatory sessions is captured by the intercept after controlling for PROF, and the estimated coefficients for UF and UR represent differences between these session means and the mean for the discriminatory sessions. We estimate the model with all 20 sessions and with the 12 sessions where fewer than $50 \%$ of the auctions result in the perfectly collusive outcome. This is a robustness test since group dynamics and cohort effects may play a role in achieving perfect collusion - independent of the role of the mechanism. Results are reported in Table 4. 
The revenue differences between the uniform-fixed and uniform-reducible mechanisms and between the uniform-fixed and discriminatory-price mechanism are not significant under either data grouping. Revenue under the uniform- reducible mechanism exceeds that under the discriminatory mechanism for both data groupings with the differences significant at the $10 \%$ level in two-tailed tests. The coefficient on the indicator for professionals is positive and significant at the $1 \%$ and $10 \%$ level, respectively, for the two data groupings, indicating higher revenue in these sessions. Importantly, for both subject types, the revenue in the discriminatory auctions is lower than the average revenue from the two uniform-price auctions over the last four auctions.

The weight of the evidence suggests a significant revenue difference between the discriminatory and uniform-reducible mechanisms, weak evidence of a difference between the discriminatory and uniform-fixed mechanisms, and little evidence for a difference between the uniform-price mechanisms. While the global average revenue comparisons and Figure 3 indicate that the use of reducible supply generates price competition between the bidders relative to the uniform-fixed auction this result is not significant. The finding that discriminatory pricing results in the lowest average revenue is significant and contrary to our expectation.

This revenue difference between the discriminatory and uniform-price mechanisms is not caused by a larger number of cohorts facing discriminatory auctions having experience with the collusive level of revenue (442 Francs): a comparable number of sessions using uniform-pricing experience this level of revenue at least once (5 of 7 under uniform-fixed, 4 of 6 under uniform-reducible, and 5 of 7 under discriminatory). Rather, the difference is caused by the greater propensity for revenue to 
converge to the collusive level under the discriminatory mechanism: weighting each session equally, once this level of revenue has been achieved it is repeated in $86.7 \%$ of subsequent auctions. In the uniform-fixed and uniform-reducible mechanisms, these percentages are $62.1 \%$ and $53.8 \%$, respectively. Excluding the perfectly collusive sessions, the difference is even greater with $66.7 \%$ of subsequent auctions achieving the collusive level of revenue under the discriminatory rule, and only $33.3 \%$ and $7.7 \%$ under the uniform-fixed and uniform-reducible mechanisms, respectively. ${ }^{17}$

\subsection{Allocations}

Along with revenue maximization, Treasuries seek to establish a liquid secondary market for their securities. For this reason, broad bidder participation in their auctions and low concentration of auction awards are major objectives in auction design. ${ }^{18}$

We begin our examination of award concentration across the different mechanisms with Figure 4. This figure illustrates that the most frequent allocation of units across bidders is the perfectly symmetric allocation of 5.2 units per bidder. There are, however, significant differences in the level of asymmetry of allocations across the mechanisms. While in the discriminatory auctions $69 \%$ of the allocations were for between 5 and 6 units, for both uniform-price mechanisms only 41\% of allocations were for between 5 and 6 units.

\footnotetext{
${ }^{17}$ Testing the Discriminatory auctions against a combination of the two versions of the Uniform-price auctions and using each auction as an observation both of these differences (whether or not the perfectly collusive sessions are excluded) are significant at better than the $1 \%$ level.

${ }^{18}$ Malvey, Archibald, and Flynn (1995) report that broadening participation and reducing award concentration were primary objectives in the U.S. experiment with uniform-price auctions held between 1992 and 1994. In addition, the U.S. Treasury prohibits individual dealers from buying more than 35\% of any auction. The effect of award concentration on the secondary market has been studied in the context of the 1991 Salomon Brothers squeeze (Jegadeesh (1993)).
} 
We examine the symmetry of allocations across the subjects using the Herfindahl - Hirschman (HH) index, which sums the squares of the percentage allocations to the bidders. If allocations are perfectly symmetric, the value of the index is 2000 , while if a single bidder receives the entire allocation, its value is 10,000. The symmetric allocation is expected on average as there is no ex ante reason to consider the bidders as asymmetric. Table 5 reports that overall the discriminatory auctions result in the lowest average concentration, while the uniform-reducible auctions result in the highest.

Panel B of Figure 5 indicates that the most striking impact of experience on the HH index is in the discriminatory auctions where by auction 11, allocations are perfectly symmetric in 6 of the 7 sessions, and nearly so in the seventh. Asymmetry also decreases significantly in the uniform-reducible auctions, although over the last 4 auctions the $\mathrm{HH}$ index remains significantly higher (59\%) than under the discriminatory sessions. There are no experience-induced patterns in symmetry of allocations under the uniform-fixed mechanism. Experience changes the asymmetry ranking of the three mechanisms relative to the global averages: the discriminatory pricing rule results in the most symmetric allocations at any level of experience, however the uniform-reducible mechanism converges to more symmetric allocations than the uniform-fixed mechanism.

We use the same data analysis strategy as in Section 4.3; i.e., we first perfectly control for experience effects and then test for differences using session level data. We initially averaged the HH index of all seven (six in the reducible mechanism) sessions for each of the three mechanisms according to their sequence (1-14) to get an average sequence of the index for each mechanism. We then compare the first period's index level under each mechanism, and then the second period's, and so on. 
The following asymmetry rankings hold with p-values for the non-parametric randomization test and t-test reported respectively: $\mathrm{HH}_{\mathrm{UF}}>\mathrm{HH}_{\mathrm{UR}}$ so allocations are more asymmetric in the uniform-fixed auctions than the uniform-reducible auctions, but the difference is only marginally significant $(\mathrm{p}=0.13$ and $\mathrm{p}=0.12) ; \mathrm{HH}_{\mathrm{UF}}>\mathrm{HH}_{\mathrm{D}}(\mathrm{p}=0.10$ and $\mathrm{p}=0.10)$; and $\mathrm{HH}_{\mathrm{UR}}>\mathrm{HH}_{\mathrm{D}}(\mathrm{p}<0.01$ and $\mathrm{p}<0.01)$.

We next analyze the data controlling for experience effects. Given the differential rates of change in experimental outcomes across mechanisms as subjects become experienced (Figure 5, Panel B), we again control for within-session experience effects by analyzing the last four auctions from each session. We calculate the average $\mathrm{HH}$ index level over the last four auctions of each session and then use each session mean as a single data point in the following (OLS) regression:

$$
\text { HH-INDEX }=b_{1}+b_{2} U F+b_{3} U R+b_{4} P R O F+e .
$$

Variable definitions are the same as in Section 4.3. We again estimate the model with all 20 sessions and as a robustness test, with the 12 sessions where fewer than $50 \%$ of the auctions result in the perfectly collusive outcome. Results are reported in Table 6.

Differences in allocation asymmetry between the uniform-fixed and uniformreducible mechanisms are not significant for either sample. The discriminatory auction resulted in significantly more symmetric allocations than either uniform-price mechanism. Allocation asymmetry under the uniform-fixed mechanism was greater than under the discriminatory mechanism for both samples, with the difference significant at the $5 \%$ level and $1 \%$ levels, respectively, for a two-tailed test. The uniform-reducible mechanism also had more asymmetric allocations than the discriminatory-price mechanism in both samples with the differences being significant at the $10 \%$ level and $1 \%$ levels, respectively. The coefficient on the indicator for professionals is insignificant. 
The strongest and most important revenue and allocation results are the significantly greater symmetry of allocation and significantly lower revenue under the discriminatory mechanism. Unfortunately, this may suggest that higher revenue and more symmetric allocations are competing goals. Symmetric allocations seem to play an important role in achieving the collusive level of revenue across all three mechanisms: in $94 \%$ of the auctions where the collusive revenue outcome obtains the allocations are perfectly symmetric and this combination of revenue and allocation is more likely to occur under the discriminatory mechanism. Furthermore, under both uniform-price mechanisms, when the allocation is perfectly symmetric, the perfectly collusive outcome is always realized. The perfectly collusive outcome occurs in $89 \%$ of the discriminatory auctions for which the allocation is perfectly symmetric (the exceptions are when the unique equilibrium outcome obtains).

Auction-level results indicate that this relationship between perfectly symmetric allocations and the collusive level of revenue leads to a strong positive correlation between revenue and the $\mathrm{HH}$ index under all three mechanisms. When we divide the sample according to the different mechanisms, the highest correlation is found for the uniform-reducible auctions (0.53), followed by the uniform-fixed (0.40), and the discriminatory auctions (0.32). All the correlations are significant at the $1 \%$ level.

Since avoiding the collusive outcome with respect to revenue is of primary importance in auction design, we also consider the relationship between revenue and asymmetry when revenue exceeds the collusive level. We accomplish this by excluding from the analysis the sessions in which the perfectly collusive outcome was attained in all auctions. This weakens the relationship significantly, with the obtained correlation 
coefficients insignificantly different from zero under all three mechanisms $(\mathrm{p}=0.44$, $\mathrm{p}=0.41$, and $\mathrm{p}=0.53$ for UF, UR, and $\mathrm{D}$, respectively). Under all three mechanisms, the relationship becomes noisier in part because although the defection of a single bidder from a collusive agreement tends to both increase revenue and produce asymmetric allocations, there are many auctions in which several bidders simultaneously bid aggressively. The discriminatory auctions, in which the unique Nash equilibrium obtains, result in both high revenue and symmetric allocations. Thus, when perfect collusion is avoided, the relationship between revenue and symmetry is very weak.

\subsection{Variation in Revenue}

A further concern for a seller in a repeated setting is variation in the revenue received across similar auctions. Indexing mechanism type with $j$ and the specific session with $i$ we define the ratio: Total average revenue $e_{j} / \operatorname{Var}\left(\right.$ average revenue $\left._{\mathrm{ji}}\right)$. We find the discriminatory auction has the highest ratio, 1.06, followed by the uniform-price with reducible supply with 0.49 , and finally the uniform-price with fixed supply, 0.46 .

These results are roughly in line with the theory. Only the uniform-fixed case supports multiple equilibria and so is predicted to have the lowest ratio. And if the theoretical results are thought to hold "on average," then for a given variation in revenue for the discriminatory and the uniform-reducible auctions, the uniform-reducible auction would be predicted to have a higher ratio due to its higher expected revenue. If the seller has a strong aversion to variation in revenue, this result provides an impetus for the use of a discriminatory auction despite evidence that it leads to lower average revenue. 


\subsection{Robustness}

Our finding that the discriminatory auction results in lower revenue and more collusion than the uniform-price auction with fixed supply is in direct contrast to GNR (1996) who report lower revenue and more collusion in the uniform-price auction. It is important to recognize that our experimental design differs from that used in GNR (1996) in at least two respects. The first is the number of bidders. In our setting, five subjects bid in each round while GNR used 11. The second is the complexity of the coordination problem due to the size of the strategy space: GNR allowed the subjects to bid at three possible prices while we allowed bidding at four. It is natural to ask whether the difference in results was due to the number of subjects or the size of the strategy space.

As a robustness check we tested whether a greater number of bidders participating in a uniform-price auction encouraged the coordination found by GNR. We accomplished this by running three additional sessions with student subjects under our uniform-fixed setting using 10 subjects and 51 units for sale. The results indicate that the greater number of bidders did not induce more collusion in the uniform-fixed auction. The average equilibrium price with 10 student bidders is 18.36 while the average equilibrium price with 5 student bidders is 17.77 . As a result, our conjecture is that the size of the strategy space is a more likely cause of the differences between our results.

\section{Conclusion}

To examine multi-unit auction design we compare different auction formats in an experimental setting. Individual and aggregate bid functions are found to differ significantly from theoretical predictions. As a consequence of its greater susceptibility 
to collusion, in our experiments the discriminatory auction led to the lowest average revenue. We find some evidence that a uniform-price auction with reducible supply can result in higher average revenue as compared with a uniform-price auction with a fixed supply, although the difference is not statistically significant. Allocations in the discriminatory auctions were the most symmetric; however, this seems to derive from its susceptibility to collusion. The uniform-price auction with fixed supply had the highest variation in revenue across auctions and the discriminatory auction had the lowest.

Our revenue results are consistent with the empirical results of Umlauf (1993) who examined the Mexican T-bill auctions and found that a uniform-price auction with reducible supply led to a higher average revenue than did a discriminatory auction. The results comparing revenue under the uniform-fixed versus the discriminatory auction contradict the GNR (1996) experimental findings but are consistent with empirical evidence in Feldman and Reinhart (1995). Feldman and Reinhart studied the international monetary fund's auction of gold from 1976 to 1980 and found that revenue in the uniform-price auctions was significantly larger. Tenorio (1993) studied Zambia’s weekly auctions of foreign exchange from 1985 to 1987 and also concluded that uniformprice auctions yield greater revenue than discriminatory auctions.

The recent switch to a uniform-price mechanism by the U.S. Treasury is consistent with our result. ${ }^{19}$ To the contrary, Belgium, France, Gambia, Mexico and Tanzania have all used a uniform-price format in the past and subsequently shifted to a discriminatory mechanism (Bartolini and Cottarelli (1997)). However, any of these decisions may have resulted from objectives other than revenue maximization.

\footnotetext{
${ }^{19}$ See the update of the Treasury Experience (October 1998).
} 


\section{References}

Ausubel, L., and P. Cramton, 1996, "Demand Reduction and Inefficiency in Multi-Unit Auctions,” University of Maryland working paper.

Back, K., and J. F. Zender, 1993, “Auctions of Divisible Goods: On the Rationale for the Treasury Experiment,” Review of Financial Studies, 6, 733-764.

Back, K and J. F. Zender, 2001, “Auctions of Divisible Goods with Endogenous Supply”, Economics Letters, 73, 29-34

Beck, N. and J. N. Katz, 1995, "What to Do (And not to Do) with Time-Series CrossSection Data,” American Political Science Review 89, 634-47.

Bartolini, L. and C. Cottarelli, 1997, "Designing Effective Auctions for Treasury Securities”, FEDERAL RESERVE BANK OF NEW YORK. Current Issues in Economics and Finance, 9.

Bernheim, D., B. Peleg, and M. Whinston, 1987, "Coalition-Proof Nash Equilibria: Concepts”, Journal of Economic Theory, 42(1), 1-12.

Cox, C. J., L. V. Smith, and M. J. Walker, 1985, "Expected Revenue in Discriminative and Uniform Price Sealed Bid Auction", Research in Experimental Economics a Research annual, Editor Smith L. Vernon, volume 3, JAI Press INC, 183-232.

Fehr, E. and U. Fischbacher, 2003, “The Nature of Human Altruism,” Nature, 425, 785791.

Feldman, R. A and V. R. Reinhart, 1995, "Flexible Estimation of Demand Schedules and Revenue under Different Auction Formats”, IMF- Working Paper No. 95/116.

Friedman, M., 1960, A Program for Monetary Stability, Fordham University Press, New York.

Goswami, G., T. Noe, and M. Rebello, 1996, “Collusion in Uniform-Price Auctions: Experimental Evidence and Implications for Treasury Auctions," Review of Financial Studies, 9, 757-785.

Jegadeesh, N., 1993, “Treasury Auction Bids and the Salomon Squeeze” Journal of Finance; 48(4), 1403-19.

Kagel, H. J., 1995, “Auctions: A Survey of Experimental Research”, The Handbook of Experimental Economics edited by Kagel H. John and Roth E. Alvin, 501-585.

Keloharju, M., K. Nyborg, and K. Rydqvist, 2002, "Strategic Behavior and Underpricing in Uniform-Price Auctions: Evidence from Finnish Treasury Auctions,” working paper. 
Klemperer, P., 2002, "What Really Matters in Auction Design," Journal of Economic Perspectives, 16(1), 169-189.

Malvey, P. F., C. M. Archibald, and S. T. Flynn (1995) "Uniform Price Auctions: Evaluation of the Treasury Experience," Report, Office of Market Finance, U.S. Treasury, Washington D.C. 20220.

Malvey, P. F. and C. M. Archibald (1998) "Uniform-Price Auctions: Update of the Treasury Experience", Report, Office of Market Finance, U.S. Treasury, Washington D.C. 20220.

Miller, J. G. and R. C. Plott, 1985, "Revenue Generating Properties of Sealed-Bid Auctions; An Experiment Analysis of One-Price and Discriminative Process", Research in Experimental Economics a Research annual, Editor Smith, Vernon L., volume 3, JAI Press INC, 159-182.

Nyborg, K., U. Bindseil and I. Strebulaev, 2002, "Bidding and Performance in Repo Auctions - Evidence from ECB Open Market Operations” working paper

Smith, L. V., 1967, "Experimental Studies of Discrimination Versus Competition in Sealed-Bid Auction Markets, Journal of Business, 40, 56-84.

Umlauf, S., 1993, “An Empirical Study of the Mexican Treasury Bill Auction,” Journal of Financial Economics, 33, 313-340.

Wang, J. J. D., and J. F. Zender, 2002, “Auctioning Divisible Goods,” Economic Theory, 19, 673-705.

Wilson, R., 1979, “Auctions of Shares,” Quarterly Journal of Economics, 93, 675-698. 


\section{Table 1}

\section{Experimental Sessions and Summary Statistics}

The table lists the experimental sessions conducted according to the date, mechanism, and the subject types (students or professionals) and reports average prices and revenues. Bidding is permitted at four prices (20, $19,18,17)$ and it is common knowledge that the resale value at the end of each auction is 20.

\begin{tabular}{lllccc}
\hline Date & Mechanism & Subjects & $\begin{array}{c}\text { Mean Stop-out } \\
\text { Price }\end{array}$ & Mean Price & $\begin{array}{c}\text { Mean } \\
\text { Revenue }\end{array}$ \\
\hline $02-26$ & Uniform-Price Fixed Supply & Students & 17.5 & 17.5 & 455 \\
$04-03$ & Uniform-Price Fixed Supply & Students & 18.5 & 18.5 & 481 \\
$04-10$ & Uniform-Price Fixed Supply & Students & 17.0 & 17.0 & 442 \\
$10-21$ & Uniform-Price Fixed Supply & Students & 18.9 & 18.9 & 490.3 \\
$10-24$ & Uniform-Price Fixed Supply & Students & 17.0 & 17.0 & 442 \\
$07-15$ & Uniform-Price Fixed Supply & Professionals & 19.8 & 19.8 & 514.4 \\
$09-10$ & Uniform-Price Fixed Supply & Professionals & 19.9 & 19.9 & 518.1 \\
& & Mean & $\mathbf{1 8 . 4}$ & $\mathbf{1 8 . 4}$ & $\mathbf{4 7 7 . 6}$ \\
& & & & & \\
$04-12$ & Uniform-Price Reducible Supply & Students & 19.2 & 19.2 & 499.6 \\
$04-16$ & Uniform-Price Reducible Supply & Students & 18.7 & 18.7 & 486.6 \\
$04-17$ & Uniform-Price Reducible Supply & Students & 17.0 & 17.0 & 442 \\
$10-25$ & Uniform-Price Reducible Supply & Students & 17.0 & 17.0 & 442 \\
$07-15$ & Uniform-Price Reducible Supply & Professionals & 19.5 & 19.5 & 506 \\
$10-15$ & Uniform-Price Reducible Supply & Professionals & 19.6 & 19.6 & 510.7 \\
& & Mean & $\mathbf{1 8 . 5}$ & $\mathbf{1 8 . 5}$ & $\mathbf{4 8 1 . 1}$ \\
& & & & & \\
$04-26$ & Discriminatory-Price Fixed Supply & Students & 17.0 & 17.0 & 442 \\
$06-10$ & Discriminatory-Price Fixed Supply & Students & 17.7 & 18.1 & 469.4 \\
$07-17$ & Discriminatory-Price Fixed Supply & Students & 17.1 & 17.9 & 465.3 \\
$10-23$ & Discriminatory-Price Fixed Supply & Students & 18.6 & 18.8 & 489.3 \\
$10-25$ & Discriminatory-Price Fixed Supply & Students & 17.0 & 17.0 & 442 \\
$07-15$ & Discriminatory-Price Fixed Supply & Professionals & 18.3 & 18.7 & 486.6 \\
$09-18$ & Discriminatory-Price Fixed Supply & Professionals & 17.0 & 17.0 & 442 \\
& & Mean & $\mathbf{1 7 . 5}$ & $\mathbf{1 7 . 8}$ & $\mathbf{4 6 2 . 4}$ \\
\hline
\end{tabular}




\section{Table 2}

\section{Comparison of the Moments of Actual to Theoretical Bidding}

Discount is measured as the difference between the secondary market price and the quantity weighted average price of a bidder's demand schedule. Standard deviation, skewness, and kurtosis are calculated according to the equations given in section 4.2. ** Significant at 5\% level (* significant at $10 \%$ level) using a two tailed t-test where the average of each session is an observation, $\mathrm{N}=7$ for uniform-fixed and discriminatory and $\mathrm{N}=6$ for uniform-reducible.

\section{2-A - Individual’s Demand Curves}

Fixed Supply, Uniform-Price

\begin{tabular}{|c|c|c|}
\hline Moments & Theory $^{20}$ & Actual \\
\hline Discount & 2.423 & 2.158 \\
\hline Standard Deviation & 1.18 & $0.24^{* *}$ \\
\hline Skewness & 1.56 & $-0.12^{* *}$ \\
\hline Kurtosis & 3.44 & 2.44 \\
\hline
\end{tabular}

Reducible Supply, Uniform-Price

\begin{tabular}{|c|c|c|}
\hline Moments & Theory & Actual \\
\hline Discount & 0 & $1.837^{* *}$ \\
\hline Standard Deviation & 0 & $0.19^{* *}$ \\
\hline Skewness & 0 & 0.03 \\
\hline Kurtosis & 1 & $1.82^{* *}$ \\
\hline
\end{tabular}

Discriminatory

\begin{tabular}{|c|c|c|}
\hline Moments & Theory & Actual \\
\hline Discount & 1 & $2.435^{* *}$ \\
\hline Standard Deviation & 0 & $0.086^{* *}$ \\
\hline Skewness & 0 & 0.03 \\
\hline Kurtosis & 1 & $1.38^{*}$ \\
\hline
\end{tabular}

${ }^{20}$ In the table we present predictions of the equilibrium with 5 units demanded by each bidder at price 20 and 21 units 17. For the equilibrium where each bidder demands 4 units at the price of 20, one unit at 19 and 21units at 17 the predictions are: Standard Deviation $=1.12$ Skewness $=1.64$ and Kurtosis $=3.78$. For the equilibrium with 3 units demanded at 20, 2 units demanded 19, and 21 units demanded 17 the theoretical predictions are: $\mathrm{STD}=1.05$, Skeweness $=1.71$ and Kurtosis $=4.12$. 


\section{2-B - Aggregate Demand Curves}

Fixed Supply, Uniform-Price

\begin{tabular}{|c|c|c|}
\hline Moments & Theory $^{21}$ & Actual \\
\hline Discount & 2.423 & 2.012 \\
\hline Standard Deviation & 1.18 & $0.44^{* *}$ \\
\hline Skewness & 1.56 & $0.22^{* *}$ \\
\hline Kurtosis & 3.44 & $2.35^{*}$ \\
\hline
\end{tabular}

Reducible Supply, Uniform-Price

\begin{tabular}{|c|c|c|}
\hline Moments & Theory & Actual \\
\hline Discount & 0 & $1.851^{* *}$ \\
\hline Standard Deviation & 0 & $0.42^{* *}$ \\
\hline Skewness & 0 & 0.27 \\
\hline Kurtosis & 1 & $5.72^{*}$ \\
\hline
\end{tabular}

Discriminatory

\begin{tabular}{|c|c|c|}
\hline Moments & Theory & Actual \\
\hline Discount & 1 & $2.44^{* *}$ \\
\hline Standard Deviation & 0 & $0.21^{* *}$ \\
\hline Skewness & 0 & -0.09 \\
\hline Kurtosis & 1 & 4.06 \\
\hline
\end{tabular}

${ }^{21}$ In the table we present the theoretical results of the equilibrium with 25 units demanded at price 20 and 105 units demanded at price 17. For completeness, the theory predictions for the equilibrium: 15 units demanded at 20, 10 units demanded at 19, 0 demanded at 18 and 105 demanded at 17 are as follows: Std= 1.0470, Skewness $=1.7091$ and Kurtosis $=4.1169$. For the equilibrium: 20 units demanded at 20, 5 units demanded at 19, 0 demanded at 18 and 105 demanded at 17 the theoretical predictions are as follows: Std. Dev. $=1.1174$, Skewness $=1.6402$ and Kurtosis $=3.7789$. 


\section{2-C - Aggregate Demand Curves- 6 Units}

Fixed Supply, Uniform-Price

\begin{tabular}{|c|c|c|}
\hline Moments & Theory $^{22}$ & Actual \\
\hline Discount & 0.5 & $2.353^{* *}$ \\
\hline Standard Deviation & 1.12 & $0.44^{* *}$ \\
\hline Skewness & -1.79 & $-0.17^{* *}$ \\
\hline Kurtosis & 4.2 & $1.99^{* *}$ \\
\hline
\end{tabular}

Reducible Supply, Uniform-Price

\begin{tabular}{|c|c|c|}
\hline Moments & Theory & Actual \\
\hline Discount & 0 & $1.923^{* *}$ \\
\hline Standard Deviation & 0 & $0.28^{*}$ \\
\hline Skewness & 0 & 0.34 \\
\hline Kurtosis & 1 & $2.40^{* *}$ \\
\hline
\end{tabular}

\section{Discriminatory}

\begin{tabular}{|c|c|c|}
\hline Moments & Theory & Actual \\
\hline Discount & 1 & $1.676^{* *}$ \\
\hline Standard Deviation & 0 & $0.14^{*}$ \\
\hline Skewness & 0 & -0.01 \\
\hline Kurtosis & 1 & $2.66^{* *}$ \\
\hline
\end{tabular}

\footnotetext{
${ }^{22}$ In the table we present the theoretical results of the equilibrium with 25 units demanded at price 20 and 5 units demanded at price 17. For completeness, the theory predictions for the equilibrium: 15 units demanded at 20, 10 units demanded at 19, 0 demanded at 18 and 5 demanded at 17 are as follows: Std. Dev. $=0.927$, Skewness $=-1.19$ and Kurtosis $=3.75$. For the equilibrium: 20 units demanded at 20, 5 units demanded at 19, 0 demanded at 18 and 105 demanded at 17 the theoretical predictions are as follows: Std. Dev. $=1.11$, Skewness $=-1.43$ and Kurtosis $=3.40$.
} 


\section{Table 3}

\section{Evolution of Revenue}

This table reports the evolution of revenue within experimental sessions and the standard deviation of revenue for each session. Under the uniform-price mechanism with fixed supply the unique symmetric Pareto-dominant coalition-proof equilibria implies auctioneer's revenue of 442 . Under the uniform-price mechanism with reducible supply, there is a unique equilibrium in which the competitive outcome obtains (revenue equal to 520). Under the discriminatory mechanism there is a unique equilibrium in undominated strategies in which auctioneer's revenue equals 494.

\section{Panel A: Fixed Supply, Uniform-Price}

\begin{tabular}{|c|c|c|c|c|c|c|c|c|c|c|c|c|c|c|c|c|c|}
\hline Date & $\begin{array}{c}\text { Subject } \\
\text { Type } \\
\end{array}$ & 1 & 2 & 3 & 4 & 5 & 6 & 7 & 8 & 9 & 10 & 11 & 12 & 13 & 14 & & $\begin{array}{l}\text { Std } \\
\text { Dev }\end{array}$ \\
\hline $2-26$ & Students & 442 & 442 & 442 & 494 & 442 & 520 & 494 & 442 & 442 & 442 & 442 & 442 & 442 & 442 & 455 & 26.5 \\
\hline $4-10$ & Students & 494 & 494 & 494 & 494 & 494 & 494 & 494 & 468 & 468 & 520 & 442 & 442 & 468 & 468 & & .2 \\
\hline 2 & Students & 442 & 142 & 147 & 1117 & 442 & 442 & 442 & 442 & 442 & 442 & 442 & 442 & 442 & 442 & & 0.0 \\
\hline $10-21$ & Stuc & 442 & 468 & 494 & 520 & 520 & 494 & 494 & 494 & 520 & 494 & 494 & 468 & 494 & 468 & & 22.5 \\
\hline & Stude & 442 & 442 & 442 & 442 & 442 & 442 & & 442 & & & & & 442 & 442 & & 0.0 \\
\hline 7 & Professionals & 520 & 520 & 520 & 494 & 520 & 520 & 520 & 520 & 494 & 494 & 520 & 520 & 520 & 520 & & 11.1 \\
\hline $10-09$ & Professionals & 520 & 520 & 520 & 520 & 520 & 520 & 520 & 520 & 520 & 520 & 520 & 494 & 520 & 520 & & 6.9 \\
\hline Mean & & 472 & 475 & 479 & 487 & 483 & 490 & 487 & 475 & 475 & 479 & 472 & 464 & 475 & 472 & 477.6 & 7.2 \\
\hline Std Dev & & 38.1 & 35.9 & 36.3 & 32.6 & 39.3 & 35.0 & 32.6 & 35.9 & 35.9 & 36.3 & 38.1 & 31.6 & 35.9 & 35.0 & 35.6 & \\
\hline
\end{tabular}

Panel B: Reducible Supply, Uniform-Price

\begin{tabular}{llllllllllllllllll}
\hline 04-12 & Students & 442 & 468 & 520 & 520 & 520 & 494 & 520 & 494 & 494 & 494 & 520 & 520 & 494 & 494 & $\mathbf{4 9 9 . 6}$ & 23.2 \\
$04-16$ & Students & 442 & 442 & 442 & 494 & 494 & 494 & 520 & 494 & 494 & 494 & 494 & 520 & 494 & 494 & $\mathbf{4 8 6 . 6}$ & 25.9 \\
$04-17$ & Students & 442 & 442 & 442 & 442 & 442 & 442 & 442 & 442 & 442 & 442 & 442 & 442 & 442 & 442 & $\mathbf{4 4 2}$ & 0.0 \\
$10-25$ & Students & 442 & 442 & 442 & 442 & 442 & 442 & 442 & 442 & 442 & 442 & 442 & 442 & 442 & 442 & $\mathbf{4 4 2}$ & 0.0 \\
$07-15$ & Professionals & 520 & 520 & 520 & 480 & 494 & 494 & 494 & 520 & 520 & 520 & 520 & 494 & 494 & 494 & $\mathbf{5 0 6}$ & 15.0 \\
$10-15$ & Professionals & 520 & 520 & 520 & 520 & 520 & 520 & 520 & 494 & 494 & 494 & 494 & 494 & 520 & 520 & $\mathbf{5 1 0 . 7}$ & 12.9 \\
Mean & $\mathbf{4 6 8}$ & $\mathbf{4 7 2}$ & $\mathbf{4 8 1}$ & $\mathbf{4 8 3}$ & $\mathbf{4 8 5}$ & $\mathbf{4 8 1}$ & $\mathbf{4 9 0}$ & $\mathbf{4 8 1}$ & $\mathbf{4 8 1}$ & $\mathbf{4 8 1}$ & $\mathbf{4 8 5}$ & $\mathbf{4 8 5}$ & $\mathbf{4 8 1}$ & $\mathbf{4 8 1}$ & $\mathbf{4 8 1 . 1}$ & $\mathbf{5 . 4}$ \\
Std Dev & 40.3 & 38.3 & 42.7 & 35.3 & 35.5 & 31.8 & 38.3 & 31.8 & 31.8 & 31.8 & 35.5 & 35.5 & 31.8 & 31.8 & $\mathbf{3 5 . 2}$ & \\
\hline
\end{tabular}

Panel C: Discriminatory

\begin{tabular}{llllllllllllllllll}
\hline $04-26$ & Students & 442 & 442 & 442 & 442 & 442 & 442 & 442 & 442 & 442 & 442 & 442 & 442 & 442 & 442 & $\mathbf{4 4 2}$ & 0.0 \\
$06-10$ & Students & 494 & 494 & 494 & 494 & 494 & 494 & 488 & 442 & 442 & 468 & 442 & 442 & 442 & 442 & $\mathbf{4 6 9 . 4}$ & 25.5 \\
$07-17$ & Students & 468 & 494 & 494 & 442 & 474 & 486 & 458 & 494 & 494 & 442 & 442 & 442 & 442 & 442 & $\mathbf{4 6 5 . 3}$ & 23.4 \\
$10-23$ & Students & 469 & 469 & 478 & 494 & 494 & 494 & 494 & 494 & 494 & 494 & 494 & 494 & 494 & 494 & $\mathbf{4 8 9 . 3}$ & 9.6 \\
$10-25$ & Students & 442 & 442 & 442 & 442 & 442 & 442 & 442 & 442 & 442 & 442 & 442 & 442 & 442 & 442 & $\mathbf{4 4 2}$ & 0.0 \\
$07-15$ & Professionals & 446 & 473 & 494 & 494 & 444 & 494 & 499 & 494 & 494 & 499 & 494 & 494 & 499 & 494 & $\mathbf{4 8 6 . 6}$ & 18.7 \\
$09-18$ & Professionals & 442 & 442 & 442 & 442 & 442 & 442 & 442 & 442 & 442 & 442 & 442 & 442 & 442 & 442 & $\mathbf{4 4 2}$ & 0.0 \\
Mean & & $\mathbf{4 5 8}$ & $\mathbf{4 6 5}$ & $\mathbf{4 6 9}$ & $\mathbf{4 6 4}$ & $\mathbf{4 6 2}$ & $\mathbf{4 7 1}$ & $\mathbf{4 6 6}$ & $\mathbf{4 6 4}$ & $\mathbf{4 6 4}$ & $\mathbf{4 6 1}$ & $\mathbf{4 5 7}$ & $\mathbf{4 5 7}$ & $\mathbf{4 5 8}$ & $\mathbf{4 5 7}$ & $\mathbf{4 6 2 . 4}$ & $\mathbf{4 . 6}$ \\
& 20.1 & 23.6 & 26.3 & 27.8 & 24.9 & 26.9 & 26.3 & 27.8 & 27.8 & 25.9 & 25.4 & 25.4 & 26.6 & 25.4 & $\mathbf{2 5 . 7}$ & \\
\hline
\end{tabular}


Table 4

\section{Auctioneer's Revenue by Mechanism}

We estimate the following model (OLS) in order to examine mechanism dependent differences in auctioneer's revenue:

$$
\text { REVENUE }=b_{1}+b_{2} U F+b_{3} U R+b_{4} P R O F+e
$$

In order to control for within-session experience effects, we analyze the last four auctions from each session. These are the auctions most likely to represent equilibrium outcomes (see Figure 5). We calculate the average revenue over the last four auctions and then use each session mean as a single data point. UF is an indicator variable that takes on the value of 1 in uniform-price fixed supply sessions and 0 otherwise. UR is an equivalent indicator variable for uniform-price fixed supply sessions. PROF is an indicator variable that takes on the value of 1 for sessions with fixed-income professionals as subjects, and 0 otherwise. The indicator for the discriminatoryprice mechanism is suppressed. Therefore the mean for the discriminatory-price sessions is captured by the intercept after controlling for PROF, and the estimated coefficients for UF and UR represent differences between these session means and the mean for the discriminatory-price sessions. We estimate the model with all sessions, and with sessions where fewer than $50 \%$ of the auctions result in the perfectly collusive outcome. This is a robustness test since group dynamics and cohort effects may play a role in achieving perfect collusion - independent of the role of the mechanism.

\begin{tabular}{ccccccc}
\hline & $\hat{b}_{1}$ & $\hat{b}_{2}$ & $\hat{b}_{3}$ & $\hat{b}_{4}$ & Adj R & Sessions/Auctions \\
& & $\mathrm{UF}$ & $\mathrm{UR}$ & $\mathrm{PROF}$ & & \\
All & 446.38 & 13.75 & 24.36 & 37.29 & 0.44 & $20 / 80$ \\
Sessions & $(43.58)$ & $(1.01)$ & $(1.72)$ & $(3.00)$ & & \\
& $\mathrm{p}<0.01$ & $\mathrm{p}=0.33$ & $\mathrm{p}=0.10$ & $\mathrm{p}=0.01$ & & \\
Competitive & 461.43 & 17.18 & 28.56 & 27.52 & 0.42 & $12 / 48$ \\
Sessions & $(42.46)$ & $(1.14)$ & $(1.90)$ & $(2.19)$ & & \\
& $\mathrm{p}<0.01$ & $\mathrm{p}=0.29$ & $\mathrm{p}=0.09$ & $\mathrm{p}=0.06$ & & \\
\hline
\end{tabular}




\section{Table 5}

\section{Herfindahl - Hirschman Index for Allocation of Units}

The table reports the Herfindahl - Hirschman index for each of the 14 auctions in each experimental session. The index is calculated by squaring the percentage allocation of each bidder and then summing the squared allocations. If allocations are perfectly symmetric, the value of the index is 2000 while if a single bidder receives the entire allocation the value is 10,000. The unique equilibrium for both the uniform-price reducible supply and discriminatory mechanisms implies perfectly symmetric allocations and hence an index value of 2000. Under the uniform-price fixed supply mechanism there are many equilibria with both symmetric and asymmetric allocations.

Panel A: Uniform-Price Fixed Supply

\begin{tabular}{|c|c|c|c|c|c|c|c|c|c|c|c|c|c|c|c|c|}
\hline Session & 1 & 2 & 3 & 4 & 5 & 6 & 7 & 8 & 9 & 10 & 11 & 12 & 13 & 14 & Mean & $\begin{array}{l}\text { Std } \\
\text { Dev }\end{array}$ \\
\hline $02-26$ & 2000 & 2000 & 2500 & 10000 & 8038 & 3769 & 3817 & 2000 & 2000 & 2000 & 2000 & 2000 & 2000 & 2000 & 3295 & 2537 \\
\hline $04-10$ & 2667 & 3285 & 4003 & 4385 & 3902 & 3500 & 2840 & 6893 & 5594 & 5396 & 2546 & 2613 & 5735 & 6037 & 4243 & 1448 \\
\hline $04-3$ & 2000 & 2000 & 2000 & 2000 & 2000 & 2000 & 2000 & 2000 & 2000 & 2000 & 2000 & 2000 & 2000 & 2000 & 2000 & 0 \\
\hline $10-21$ & 3395 & 2923 & 6110 & 3169 & 4549 & 3050 & 2548 & 3487 & 3469 & 3734 & 3750 & 10000 & 4181 & 6302 & 4333 & 1970 \\
\hline $10-24$ & 2000 & 2000 & 2000 & 2000 & 2000 & 2000 & 2000 & 2000 & 2000 & 2000 & 2000 & 2000 & 2000 & 2000 & 2000 & 0 \\
\hline $07-15$ & 4941 & 4463 & 7619 & 7313 & 3965 & 3930 & 3859 & 4050 & 6674 & 3008 & 3410 & 4054 & 3887 & 3501 & 4620 & 1483 \\
\hline $10-09$ & 2732 & 2990 & 2966 & 3899 & 2814 & 3005 & 3126 & 3206 & 3143 & 2814 & 3158 & 6541 & 2790 & 2690 & 3277 & 987 \\
\hline Mean & 2819 & 2809 & 3885 & 4681 & 3895 & 3036 & 2884 & 3377 & 3554 & 2993 & 2695 & 4173 & 3228 & 3504 & 3395 & 590 \\
\hline Std Dev & 1071 & 910 & 2190 & 2960 & 2080 & 785 & 770 & 1758 & 1885 & 1246 & 743 & 3060 & 1434 & 1901 & 1081 & \\
\hline \multicolumn{17}{|c|}{ Panel B: Uniform-Price Reducible Supply } \\
\hline 04-12 & 2000 & 10000 & 7686 & 10000 & 7290 & 2003 & 8671 & 2027 & 5000 & 3553 & 4692 & 4491 & 2167 & 2119 & 5121 & 3055 \\
\hline 04-16 & 3575 & 6246 & 6226 & 3640 & 7290 & 2962 & 5495 & 2003 & 3744 & 2880 & 5355 & 2990 & 4275 & 4113 & 4342 & 1546 \\
\hline 04-17 & 2000 & 2000 & 2000 & 2000 & 2000 & 2000 & 2000 & 2000 & 2000 & 2000 & 2000 & 2000 & 2000 & 2000 & 2000 & 0 \\
\hline $10-25$ & 2000 & 2000 & 2000 & 2000 & 2000 & 2000 & 2000 & 2000 & 2000 & 2000 & 2000 & 2000 & 2000 & 2000 & 2000 & 0 \\
\hline 07-15 & 4077 & 5022 & 9482 & 8521 & 4017 & 2497 & 4207 & 4070 & 5597 & 4068 & 4063 & 3228 & 4270 & 4469 & 4828 & 1916 \\
\hline $10-15$ & 4132 & 4813 & 5081 & 4687 & 5339 & 6101 & 5850 & 6253 & 2820 & 4065 & 3973 & 4050 & 3775 & 2951 & 4564 & 1079 \\
\hline Mean & 2964 & 5014 & 5413 & 5141 & 4656 & 2926 & 4704 & 3086 & 3527 & 3094 & 3680 & 3127 & 3081 & 2942 & 3811 & 984 \\
\hline Std Dev & 1074 & 2986 & 3026 & 3383 & 2402 & 1602 & 2551 & 1769 & 1527 & 953 & 1393 & 1028 & 1140 & 1110 & 1853 & \\
\hline \multicolumn{17}{|c|}{ Panel C: Discriminatory } \\
\hline $04-26$ & 2000 & 2000 & 2000 & 2000 & 2000 & 2000 & 2000 & 2000 & 2000 & 2000 & 2000 & 2000 & 2000 & 2000 & 2000 & 0 \\
\hline $06-10$ & 3798 & 2550 & 2249 & 2448 & 2017 & 2010 & 6914 & 2000 & 2000 & 10000 & 2000 & 2000 & 2000 & 2000 & 3142 & 2381 \\
\hline $07-17$ & 6745 & 10000 & 5027 & 2000 & 4518 & 3724 & 4518 & 5000 & 2926 & 2000 & 2000 & 2000 & 2000 & 2000 & 3890 & 2340 \\
\hline $10-23$ & 9257 & 9257 & 10000 & 2523 & 2238 & 2162 & 2373 & 2000 & 2000 & 2000 & 2000 & 2000 & 2000 & 2000 & 3701 & 3154 \\
\hline $10-25$ & 2000 & 2000 & 2000 & 2000 & 2000 & 2000 & 2000 & 2000 & 2000 & 2000 & 2000 & 2000 & 2000 & 2000 & 2000 & 0 \\
\hline $07-15$ & 2124 & 3619 & 6197 & 2473 & 2031 & 7290 & 2193 & 2422 & 2067 & 2225 & 2151 & 2067 & 2120 & 2017 & 2928 & 1681 \\
\hline 09-18 & 2000 & 2000 & 2000 & 2000 & 2000 & 2000 & 2000 & 2000 & 2000 & 2000 & 2000 & 2000 & 2000 & 2000 & 2000 & 0 \\
\hline Mean & 3989 & 4489 & 4210 & 2206 & 2400 & 3027 & 3143 & 2489 & 2142 & 3175 & 2022 & 2010 & 2017 & 2002 & 2809 & 881 \\
\hline Std Dev & 2908 & 3564 & 3072 & 258 & 938 & 1984 & 1894 & 1118 & 347 & 3011 & 57 & 25 & 45 & 6 & 822 & \\
\hline
\end{tabular}




\section{Table 6 \\ Allocation Symmetry by Mechanism}

We estimate the following model (OLS) in order to examine mechanism-dependent differences in the symmetry of allocations:

$$
\mathrm{HH}=\mathrm{b}_{1}+\mathrm{b}_{2} \mathrm{UF}+\mathrm{b}_{3} \mathrm{UR}+\mathrm{b}_{4} \mathrm{PROF}+\mathrm{e}
$$

Our measure of symmetry is the Herfindahl - Hirschman index (HH). The index is calculated by squaring the percentage allocation of each bidder and then summing the squared allocations. We multiply this sum by 10,000 to remove decimals. If allocations are perfectly symmetric, the value of the index is 2000 while if a single bidder receives the entire allocation the value is 10,000 . In order to control for within-session experience effects, we analyze the last four auctions from each session. These are the auctions most likely to represent equilibrium outcomes (see Figure 5). We calculate the average level of $\mathrm{HH}$ over the last four auctions in each session and then use each session mean as a single data point. UF is an indicator variable that takes on the value of 1 in uniform-price fixed supply sessions and 0 otherwise. UR is an equivalent indicator variable for uniform-price fixed supply sessions. PROF is an indicator variable that takes on the value of 1 for sessions with fixed-income professionals as subjects, and 0 otherwise. The indicator for the discriminatory-price mechanism is suppressed. Therefore the mean for the discriminatory-price sessions is captured by the intercept after controlling for PROF, and the estimated coefficients for UF and UR represent differences between these session means and the mean for the discriminatory-price sessions. We estimate the model with all sessions, and with sessions where fewer than $50 \%$ of the auctions result in the perfectly collusive outcome. This is a robustness test since group dynamics and cohort effects may play a role in achieving perfect collusion independent of the role of the mechanism.

\begin{tabular}{ccccccc}
\hline & $\hat{b}_{1}$ & $\hat{b}_{2}$ & $\hat{b}_{3}$ & $\hat{b}_{4}$ & Adj R $^{2}$ & Sessions/Auctions \\
& & $\mathrm{UF}$ & $\mathrm{UR}$ & $\mathrm{PROF}$ & & \\
All & 1873 & 1387 & 1172 & 489 & 0.21 & $20 / 80$ \\
Sessions & $(4.42)$ & $(2.47)$ & $(2.00)$ & $(0.95)$ & & \\
& $\mathrm{p}<0.01$ & $\mathrm{p}=0.03$ & $\mathrm{p}=0.06$ & $\mathrm{p}=0.35$ & & \\
Competitive & 2136 & 2541 & 1903 & -455 & 0.72 & $12 / 48$ \\
Sessions & $(6.25)$ & $(5.37)$ & $(4.02)$ & $(-1.16)$ & & \\
& $\mathrm{p}<0.01$ & $\mathrm{p}<0.01$ & $\mathrm{p}<0.01$ & $\mathrm{p}=0.28$ & & \\
\hline
\end{tabular}




\section{Figure 1}

\section{Average Number of Submitted Price-Quantity Combinations}

This figure shows the percentage of auctions under each mechanism in which a given number of subjects submitted more than one price quantity combination.

Uniform-Fix

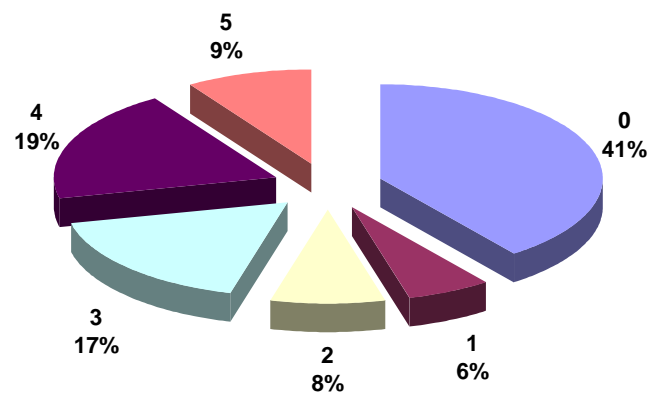

Uniform - Reducible

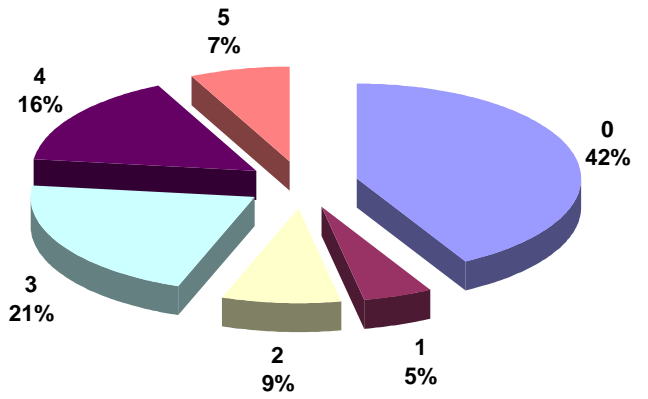

\section{Discriminatory}

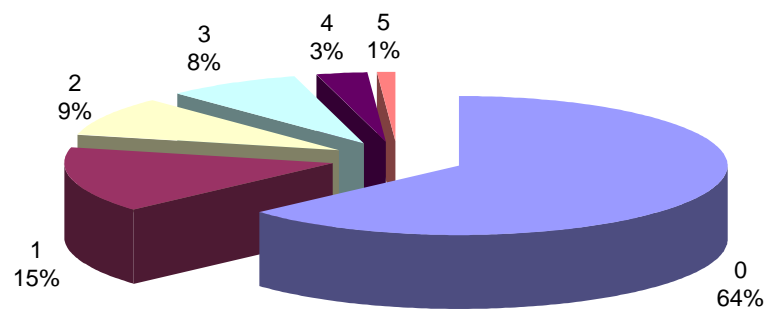




\section{Figure 2}

Theoretical equilibrium demand curves and the actual average aggregate demands for each mechanism.
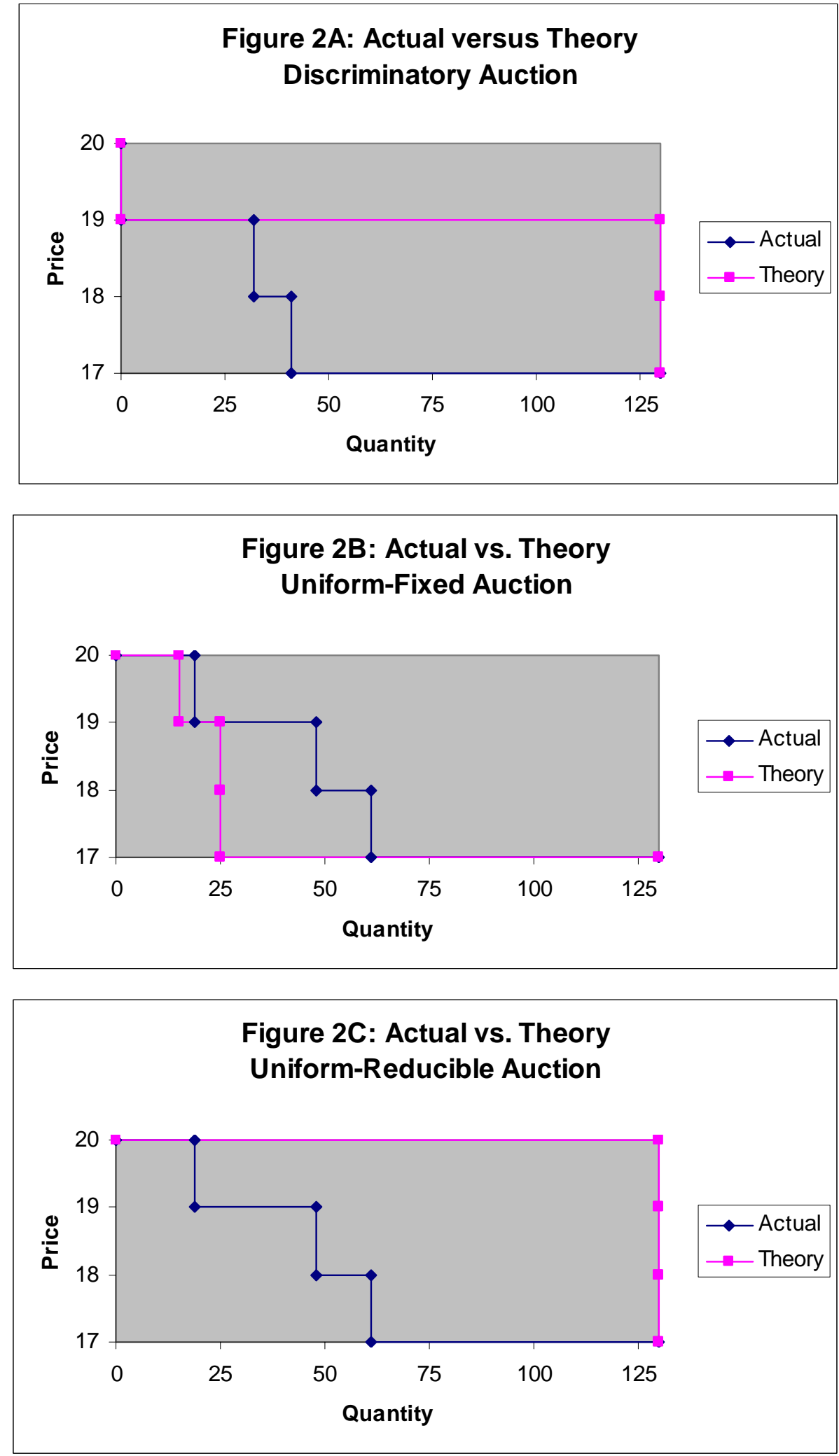


\section{Figure 3}

Actual average aggregate demand curves across mechanisms.

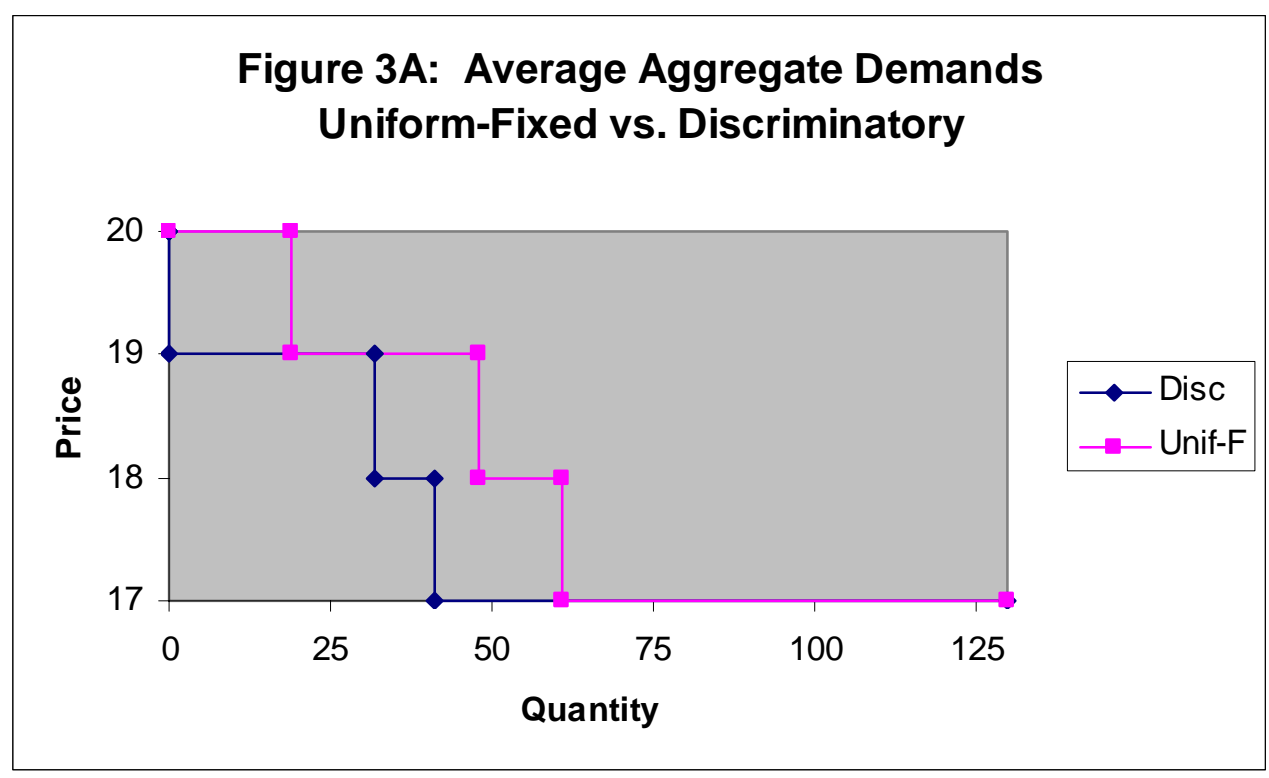

Figure 3B: Average Aggregate Demands UniformFixed vs. Uniform Reducible

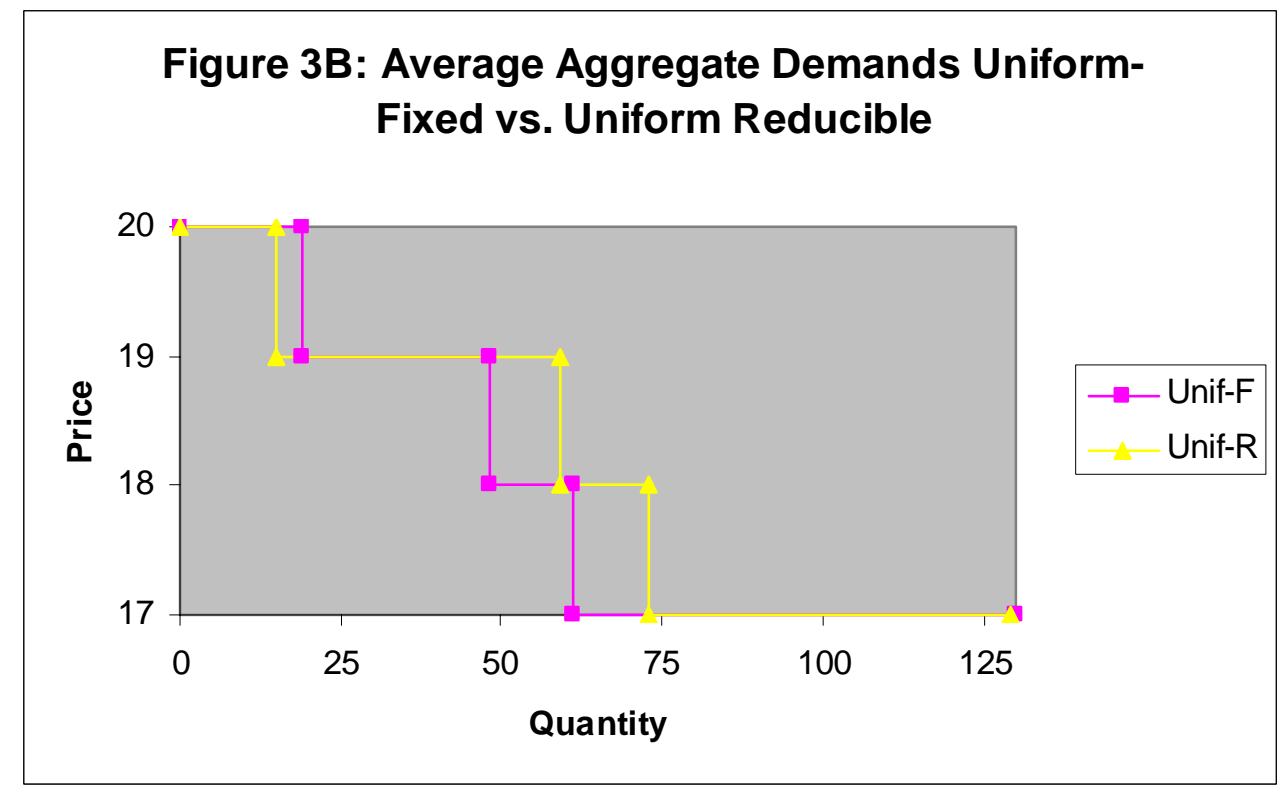

Mean Aggregate Inverse Demand

\begin{tabular}{|c|c|c|c|}
\hline Prices & Discriminatory & Uniform-Fix & Uniform-Reducible \\
\hline 20 & 0.15 & 9.97 & 15.08 \\
\hline 19 & 32.02 & 30.95 & 59.32 \\
\hline 18 & 39.85 & 43.55 & 72.83 \\
\hline 17 & 129.54 & 129.58 & 128.65 \\
\hline
\end{tabular}




\section{Figure 4}

\section{The Distribution of Allocations}

This figure shows how the symmetry of the allocation of units to subjects differs across mechanisms by depicting the frequency with which allocations to a bidder in an auction occurred in the depicted intervals. Symmetric equilibria imply allocations of 5.2 units per subject.

\section{Discriminatory}

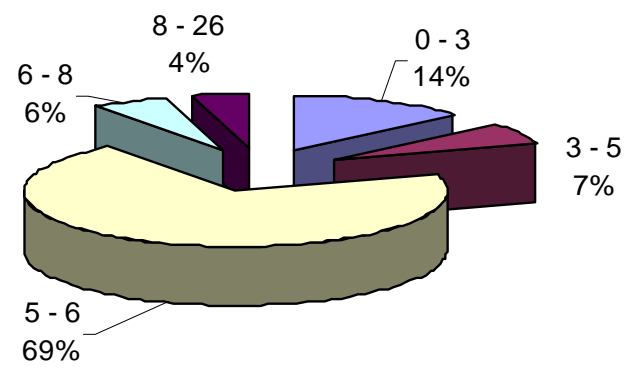

Uniform-Fixed

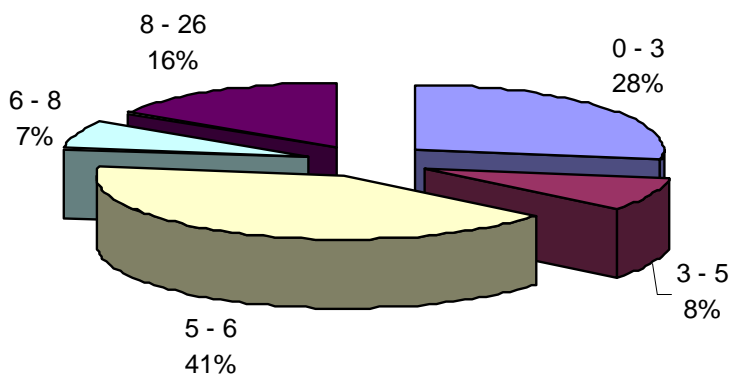

Uniform-Reducible

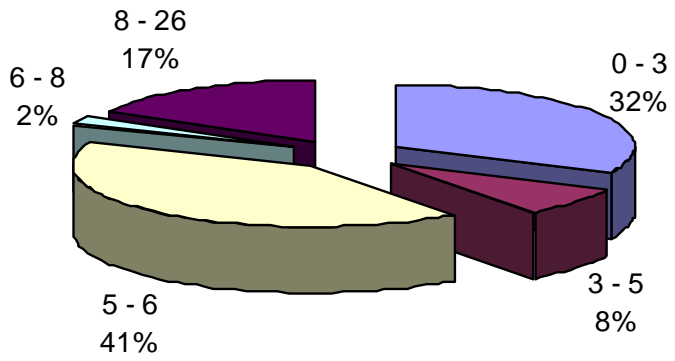


Figure 5

Experience Effects

The following panels show the influence of experience on auctioneer's revenue and the symmetry of allocations (Herfindahl-Hirshman Index) by comparing results from later auctions with global averages. The first data grouping is the global average for all 14 auctions under each mechanism, the second data grouping is the average for auctions 2 through 14, the third is the average for auctions 3 through 14 and so on.. Under the Discriminatory-price mechanism (D), auctioneer's revenue declines monotonically as bidders gain experience and the allocations converge to the perfectly symmetric by auction 11 . Under the uniform-fixed mechanism (UF), there is no significant change in symmetry while auctioneer's revenue trends downward. Under the uniform-reducible mechanism (UR), the reverse is true: symmetry increases significantly while there is no trend in revenue
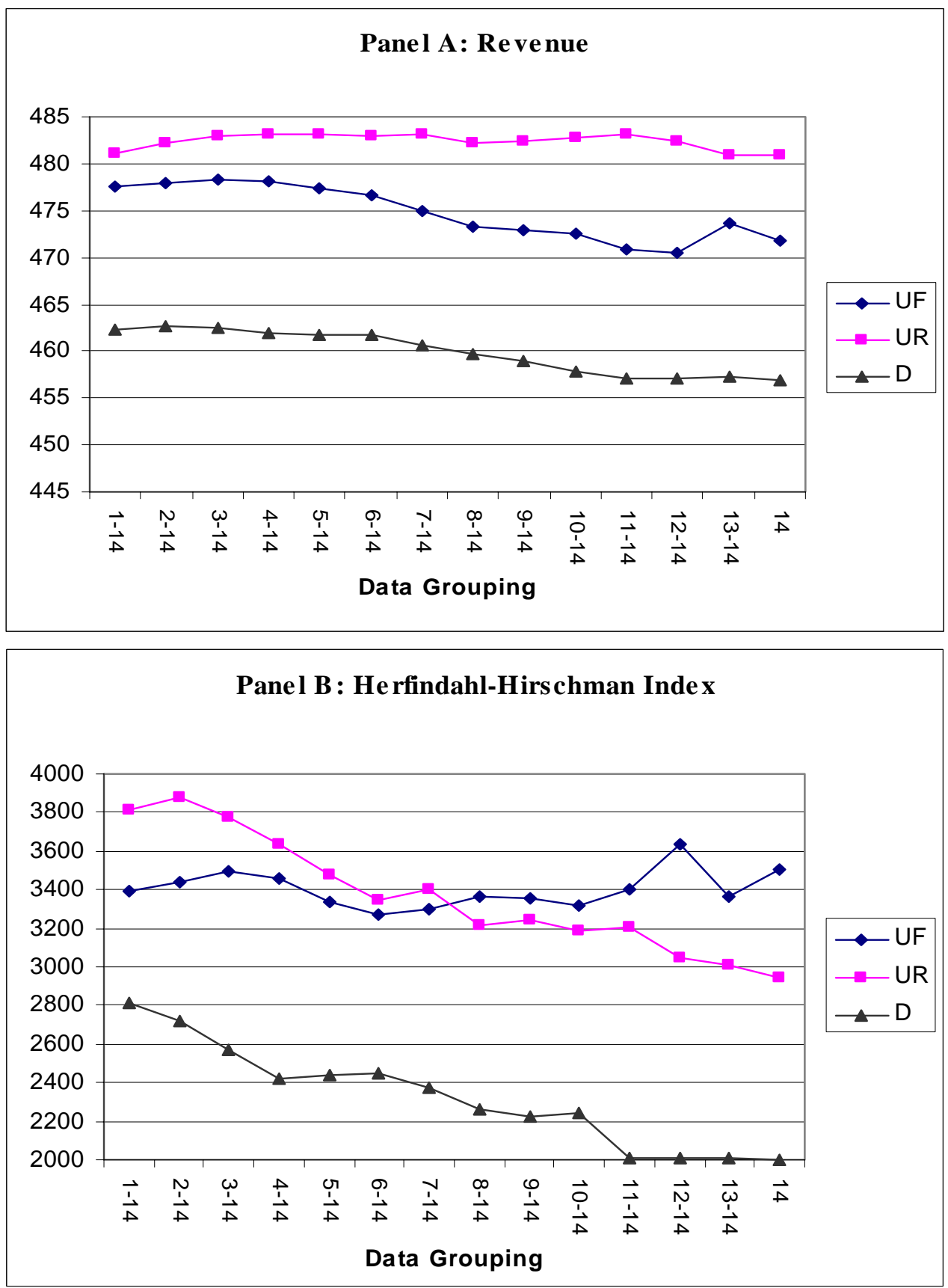


\section{Appendix - Instructions}

Auction-2 (UF-R)

This is an experiment in economic decision-making. The experiment consists of several rounds. At the end of each round your payoff for that round will be calculated. At the end of the experiment, your payoff from each round will be added up and this sum will determine your payoff for the experiment. Your payoff will be made with funds provided through grants by various institutions. Please feel free to earn as much of this money as possible. Everything contained in these instructions and everything you hear in this session is an accurate representation of this experiment. Be sure to ask any questions that you may have during this instruction period, and ask for assistance, if needed, at any time. All subjects receive the same instructions.

There are four parts in today's experiment:

1. These instructions

2. The trading game consisting of a random number of auctions

3. A questionnaire

4. The (private) payment of earnings

\section{THE TRADING GAME OVERVIEW}

In this experiment you will be required to bid for units of a good which we will call widgets. There will be 26 widgets available to all players. The resale value of each widget at the end of the auction is Fr. 20. You will be submitting a schedule of bids. This schedule indicates the number of widgets you are willing to buy at a given price level. The possible price levels will be Fr. 17, Fr. 18, Fr. 19, and Fr. 20. Once all schedules have been submitted, the computer will assign widgets to players submitting the highest bids until up to the available supply of 26 widgets is exhausted (if it increases the revenue from selling widgets, the computer may automatically sell fewer than 26 widgets). All the players will pay the same price (clearing price) for each widget he/she is allocated. At the end of each auction your cash balance will increase by 20 francs for each widget you hold, so you will earn profits on each widget you purchase at a clearing price less than 20 francs. There will be multiple auctions. The exact number will be randomly chosen. At the end of the experiment your balance in francs will be converted to cash 
( 1 franc $=\$ 0.10$ ), and you will be paid that amount in cash. Only you and the assistant that pays you will learn your earnings from today's session.

\section{DETAILS}

There will be $\mathbf{2 6}$ widgets available for sale. Your resale value for each widget is $\mathbf{2 0}$ francs. (This means that after the auction your balance will increase by 20 francs for each widget that you hold, less what you paid for each widget). Prior to each auction, you will be required to submit via computer a schedule of bids. This schedule indicates the number of widgets you are willing to buy (including zero) at each possible price level. The possible price levels will be Fr. 17, Fr. 18, Fr. 19, and Fr. 20 and the sum of all of your bids may not exceed 26 units. Once each participant has submitted his/her schedule of bids, the computer will calculate the highest price at which all 26 widgets can be sold and will allocate widgets to players that submit bids that are equal to or higher than this price. The computer will also calculate the revenue generated if the number of widgets actually sold is less than 26 and it will choose to sell the quantity (less than or equal to 26) that maximizes the revenue. The price paid for each widget will be equal to the clearing price. The market-clearing price will be the highest price at which the total demand for widgets summed across all bidders is equal to $\mathbf{2 6}$ (or the highest price at which a smaller quantity of widgets chosen by the computer can be sold).

There will be several rounds of bidding. Only you will know your actual bids, allocations, and payoffs in each round, however all the participants will know the eventual clearing price of each round. You have the option to change your bids from one auction to another. The computer will end the experiment after some random number of rounds of bidding. Only the computer knows this number of rounds.

\section{The Calculation of Your Payoffs}

Your payoffs from each auction will be equal to the difference between your resale value for each widget (Fr.20) and the clearing price times the number of widgets you are allocated. At the end of each round your payoffs will be calculated. At the end of each experiment, the payoffs of each round will be added up. The sum of your round by round payoffs will determine your payoff from the experiment. 
After the experiment is ended, your cumulative dollar payoff will be determined using the following formula: \$ Payoffs = Balance in Francs * 0.10

Each participant will learn only his/her own final cash payment.

\section{COMMUNICATION RULES}

Before and after each round you may discuss strategies with the other players for about 1 minute. However you are required to remain seated behind your computer screen at all times. You are explicitly not allowed to:

1) Make physical threats of any kind or verbally abuse other players

2) Agree to share profits after the experiment

3) Look at the computer screen of any other player

4) Ask other participants how much they have earned when the experiment has ended.

The following examples are for illustrative purposes only. They are not intended to be suggested as "best" strategies and simply demonstrate the implications of a possible set of actions.

\section{Example 1}

Consider a game with 5 bidders: A, B, C, D and E. Suppose they submit the following schedules:

\begin{tabular}{|r|r|r|r|r|r|r|r|r|}
\hline & \multicolumn{5}{|c|}{ Bidders } & \multirow{2}{*}{ Demand } & $\begin{array}{l}\text { Cumulative } \\
\text { Demand }\end{array}$ & Supply \\
\hline \hline PRICE & A & B & C & D & E & & 16 & 26 \\
\hline $\mathbf{2 0}$ & 11 & 0 & 5 & 0 & 0 & 16 & 26 & 26 \\
\hline $\mathbf{1 9}$ & 5 & 0 & 3 & 2 & 0 & 10 & 63 & 26 \\
\hline $\mathbf{1 8}$ & 5 & 0 & 8 & 6 & 18 & 37 & 130 & 26 \\
\hline 17 & 5 & 26 & 10 & 18 & 8 & 67 & & 16 \\
\hline
\end{tabular}

The demand at each price is the sum of the demands of bidders A, B, C, D, and E. For example the demand at price 20 is equal to $11+0+5+0+0=16$. The cumulative demand is equal to the total demand at that price and all higher prices. For example the cumulative demand at the price of 19 is $16($ Demand at 20 $)+10($ Demand at 19$)=26$. The market-clearing price is the highest price at 
which the cumulative demand equals the supply. In this case, the cumulative demand equals the supply at price equal 19.

The allocation and profit of the players is as follows:

\begin{tabular}{|l||c|c|c|c|c|}
\hline PRICE & A & B & C & D & E \\
\hline Allocation & 16 & 0 & 8 & 2 & 0 \\
\hline Profit & $16^{*}(20-19)=16$ & $\mathbf{0}$ & $8^{*}(20-19)=\mathbf{8}$ & $2 *(20-19)=\mathbf{2}$ & $\mathbf{0}$ \\
\hline
\end{tabular}

Since the value of a widget for each player is 20, each player makes a profit for each unit that he/she bought at a price below 20. Since in this example the clearing price is 19, each participant makes a profit of 1 Fr. times the number of units he/she is allocated.

Note: At the end of each round, you will learn the total demand at each price and your own payoff, but you will not learn the bids or payoffs of any other participant.

\section{EXAMPLE 2}

The following example illustrates a case where cumulative demand does not exactly equal supply at any price, and shows how the widgets are allocated if this occurs.

\begin{tabular}{|c|c|c|c|c|c|c|c|c|}
\hline \multirow[b]{2}{*}{ PRICE } & \multicolumn{5}{|c|}{ Bidders } & \multirow[t]{2}{*}{ Demand } & \multirow{2}{*}{$\begin{array}{l}\text { Cumulative } \\
\text { Demand }\end{array}$} & \multirow[t]{2}{*}{ Supply } \\
\hline & A & B & C & D & $\mathbf{E}$ & & & \\
\hline 20 & 11 & 0 & 5 & 0 & 0 & 16 & 16 & 26 \\
\hline 19 & 5 & 0 & 3 & 2 & 8 & 18 & 34 & 26 \\
\hline 18 & 5 & 0 & 8 & 6 & 10 & 29 & 63 & 26 \\
\hline 17 & 5 & 26 & 10 & 18 & 8 & 67 & 130 & 26 \\
\hline
\end{tabular}

In this case, the market-clearing price is 19. Each player will be allocated his/her demand at price 20 and some of his/her demand at price $=19$. Each player's allocation at 19 will depend on how large his/her bid was at that price: the larger the bid the larger the allocation as follows. Player A bids for 5 units at a price of 19 . Since these 5 units represent $5 / 18$ or $27.7 \%$ of demand at 
price $=19$, this player receives $27.7 \%$ of the number of widgets necessary to make cumulative demand at price $=19$ equal 26 (the supply of widgets). Since 10 widgets will be allocated from bids at price $=19$, player $\mathrm{A}$ receives 2.8 of these widgets (27.7\% of 10 rounded to the tenth). Player A will also receive his/her entire bid of 10 at price $=20$.

Note that the computer could increase the market-clearing price to 20 by reducing the quantity of widgets sold to 16 , but will not do so in this case because this would reduce revenue (26*19 > $16 * 20)$.

The allocation and profit of the players is as follows:

\begin{tabular}{|l||c|c|c|c|c|}
\hline PRICE & A & B & C & D & E \\
\hline Allocation & 13.8 & 0 & 6.7 & 1.1 & 4.4 \\
\hline Profit & $13.8^{*}(20-19)=13.8$ & 0 & $6.7^{*}(20-19)=\mathbf{6 . 7}$ & $1.1^{*}(20-19)=\mathbf{1 . 1}$ & $4.4^{*}(20-19)=\mathbf{4 . 4}$ \\
\hline
\end{tabular}

\section{GRAPHICAL INTERFACE}

The following figures are for illustrative purposes only. They are not intended to be suggested as "best" strategies and simply demonstrate the computer interface.

Figure 1 below shows the first screen you will see when the game starts. The computer screen is divided into three main areas: The "Bid Frame" (large area on the left-upper corner), the "History Graph" (thin rectangular area on the right-upper corner) and the "History Table" (wide rectangular area on the bottom of the screen). 
Figure I

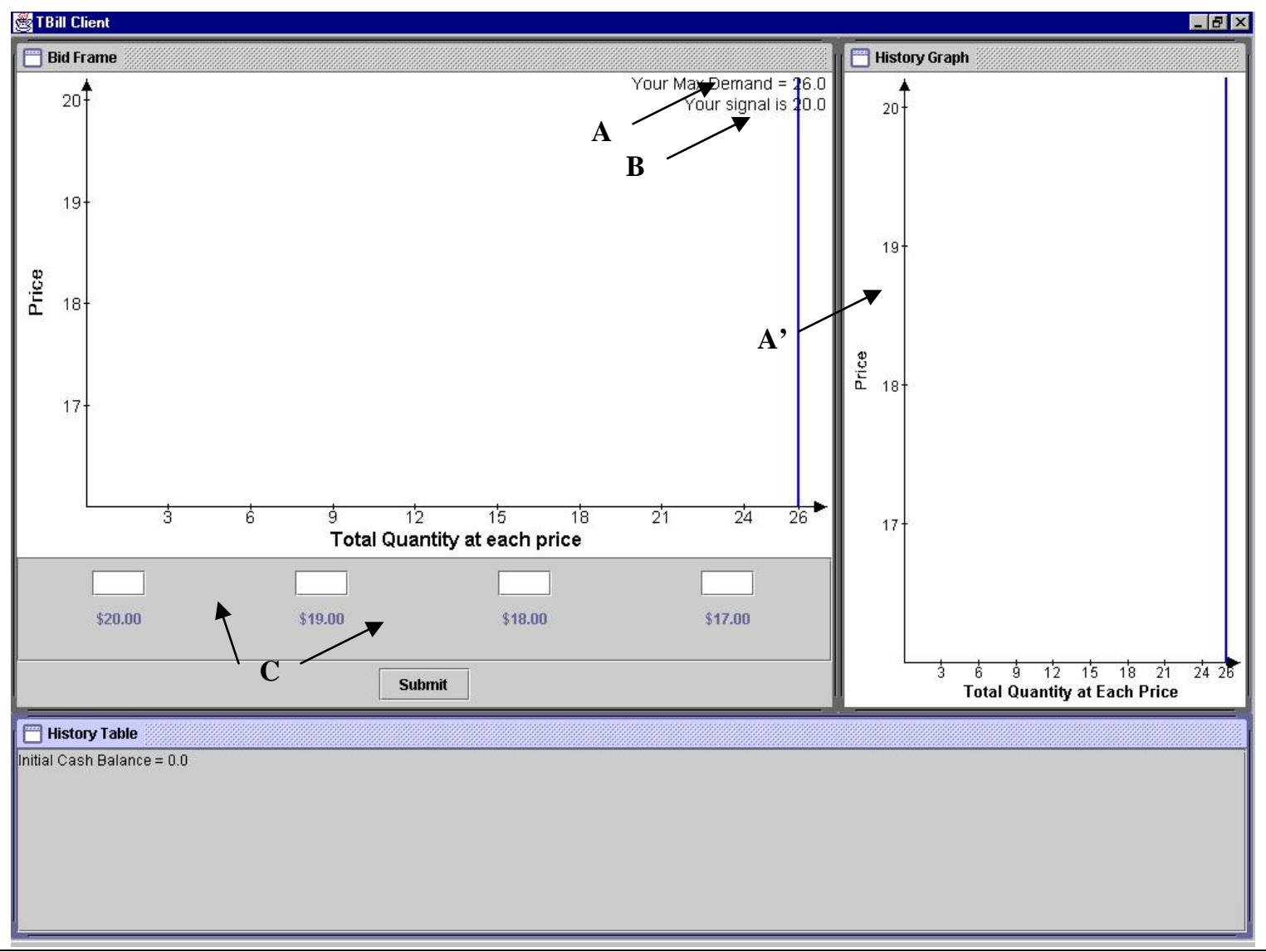

The Bid Frame is the interface that allows you to input your bids at each price. The "A" indicates your maximum demand is 26 . This is also illustrated in the graph by the blue vertical line (marked A'). Point “B” reminds you that your resale value for each widget will be Fr. 20. The white fields marked with "C" are where you will input your bids at the different prices. Notice that there is one field for each of the four allowed prices (that is Fr. 20, Fr. 19, Fr. 18 and Fr. 17). You must submit your bid at each respective price by typing a non-negative integer between 0 and 26. By default the computer positions your cursor in the Fr. 20 Field. You can move to the next field (Fr. 19) by pressing Tab on your keyboard or by clicking the field with the left button of your mouse. 
Figure 2 below shows you how the process just described works. You will notice that as you input your demand schedule in the mentioned fields, the computer will draw a demand curve (demand graph). It will look like the downward sloping ladder graph marked with the letter "D" in Figure 2.

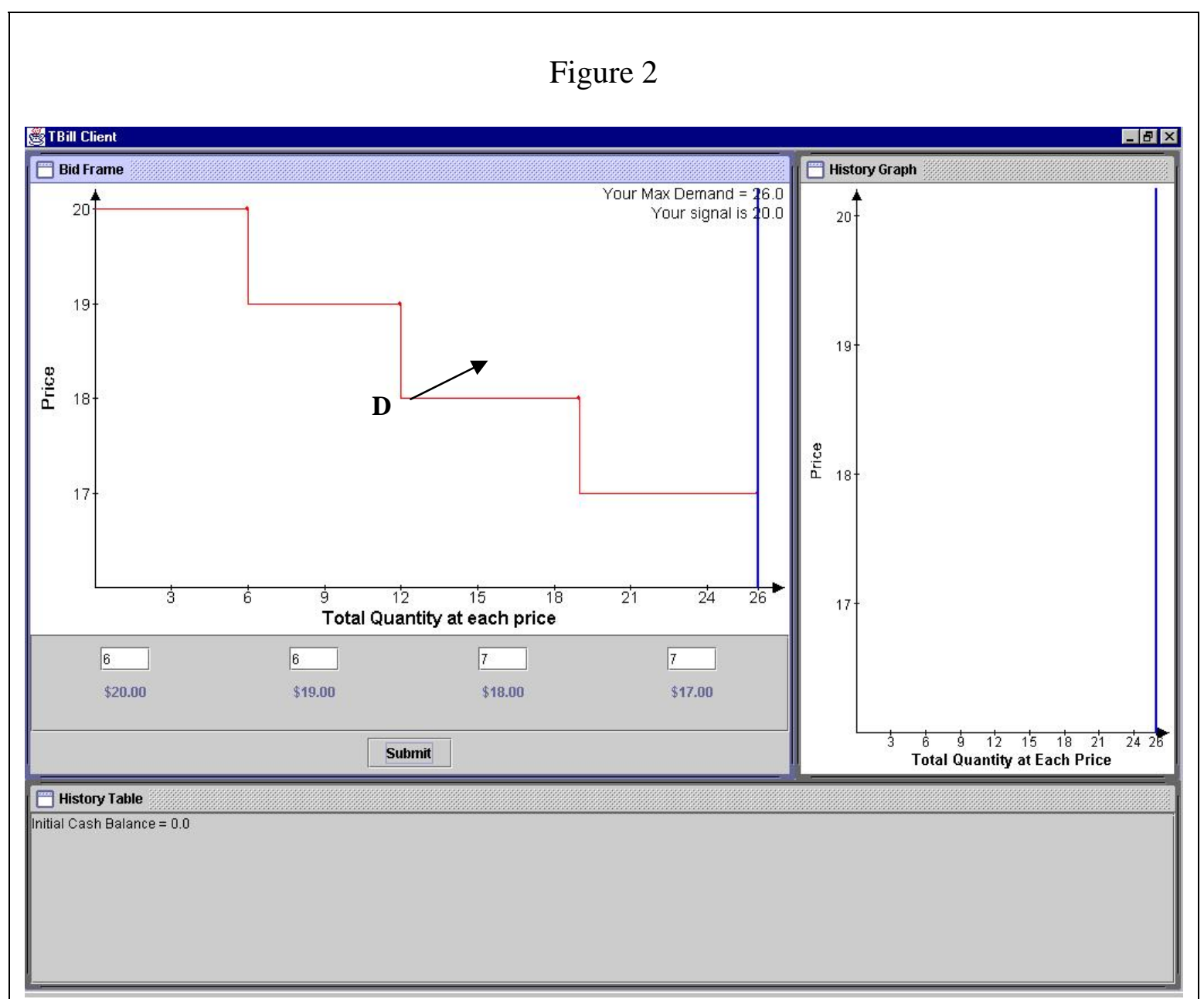

Note that the demand curve only goes as far as the maximum demand allowed (26). You are allowed to bid for less than this amount but not more. Once you are done inputting your bids, you submit them by clicking the "Submit" button on the screen with your mouse, or by "tabbing" into it with your keyboard and pressing the "Enter" key.

Once all subjects have submitted their bids, the results for the auction will be displayed. The results for the round just played will always be displayed in the same area as the "Bid Frame" (the large area on the right-upper corner of the screen). Notice however that 
the label of the Frame has changed to "Auction Results." Figure 3 shows the hypothetical results of the first round in our example. The "Auction Results" Window will show your original demand curve, the market clearing price with a dotted blue line, and will highlight with green the portion of your demand curve which was filled (in the case of our example 13 widgets).

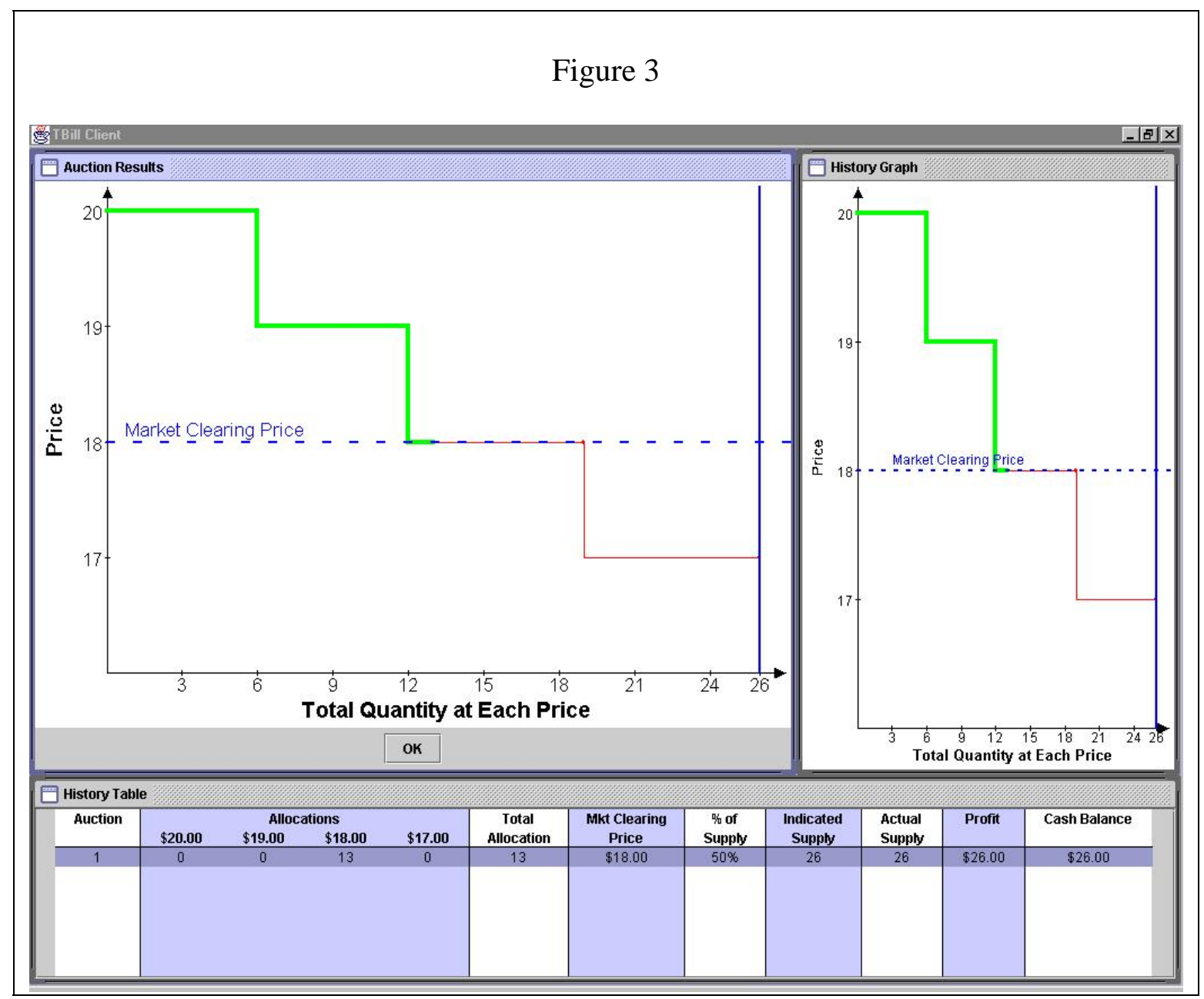

The "History Table" gives you a numerical summary of the round's results. It tells you the number of widgets you were allocated, the market-clearing price, the percentage of the overall supply of 26 widgets you received, your profits, and your cash balance. 


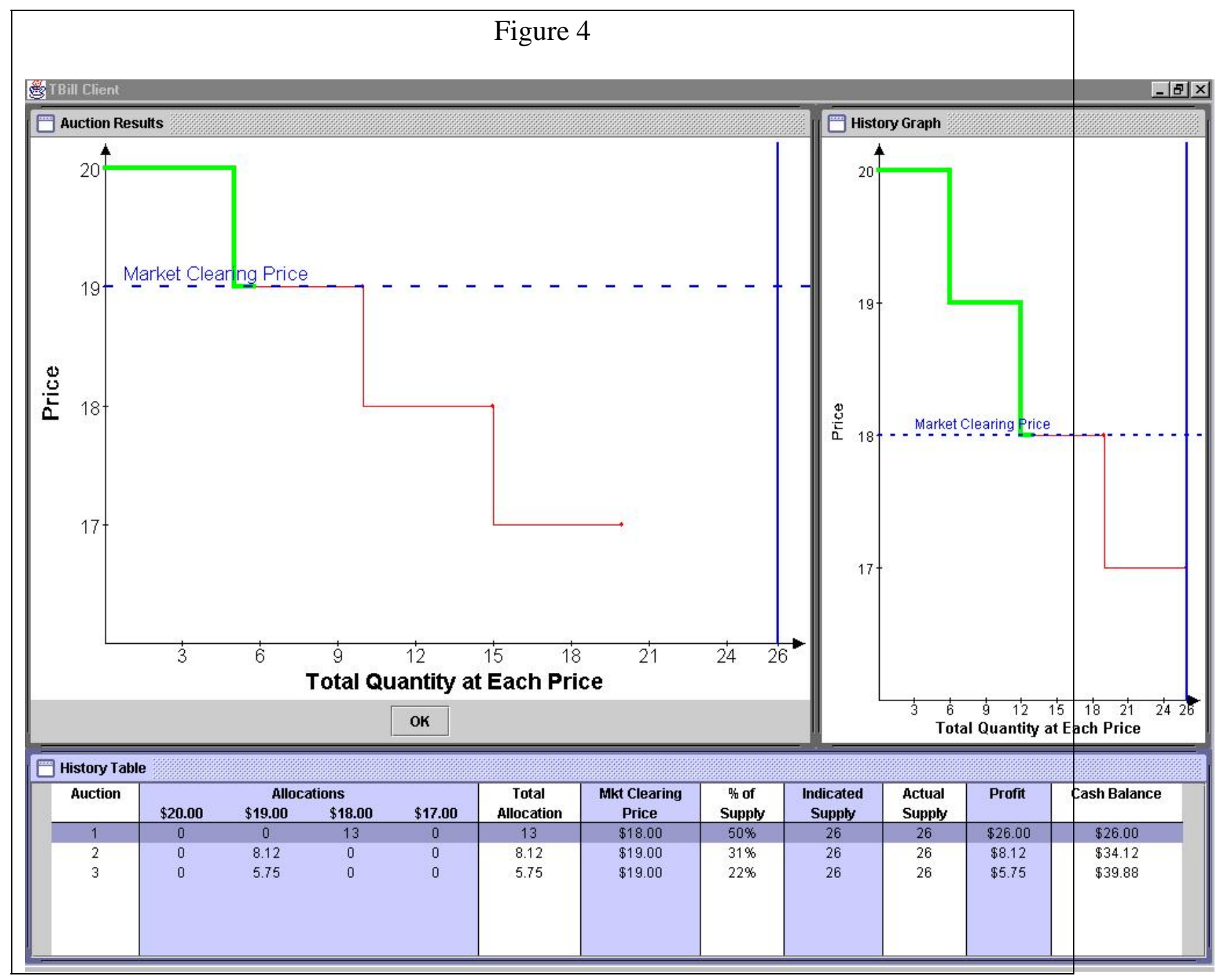

Figure 4 shows how the "History Graph” displays results from previous rounds. In this illustration, even though the game has already been played three rounds, the graph (upper right-hand corner) is showing the results of the first one. Please notice how the "Auction Results” Graph and the "History Graph” differ: the “Auction Results” Graph shows the results of the last round played (in this case round 3) and the "History Graph" is showing those of the first round.

At any point in the game you can recall the "History Graph” from past rounds by double clicking the desired round in the "History Table." Notice in Figure 4 that although the "History Table" depicts the results of all the rounds played, the first round is highlighted. 
This means that the "History Graph" shown corresponds to that highlighted round. By default, after each round, the "History Table" will highlight the last round played, but you can change this at any point of the game by highlighting the desired round. When a game lasts for more rounds than the "History Table" can show in its limited area, a scroll bar will appear to the right of the table. This allows you to view the results from any period.

The computer will randomly determine the last auction. When this occurs a screen will be displayed that reports your initial cash balance (zero) and your profits at the end of the game. If you wish you may write down your profits, but you need not do so; the experimenter has this record and will pay you your exact earnings in private. Finally, press "Enter" with the keyboard (or click "Ok" using the mouse) and your screen will go blank. If you don't do this, the screen will automatically go blank after 60 seconds. Either way, do not get up from your seat until instructed to do so.

\section{Quiz}

1. Suppose you bid for 1 widget at a price of Fr. 20, 10 widgets at a price of Fr. 19, 2 widgets at a price of Fr. 18, and 13 widgets at a price of Fr. 17. Suppose you receive all the widgets you bid for at a price greater than or equal to Fr.18, and none of the widgets you bid for at a price of Fr. 17. What is your profit in Francs for the period?

2. Assume the following set of bids.

\begin{tabular}{|c|c|c|c|c|c|c|c|c|}
\hline & \multicolumn{5}{|c|}{ Bidders } & \multirow[t]{2}{*}{ Demand } & \multirow{2}{*}{$\begin{array}{l}\text { Cumulative } \\
\text { Demand }\end{array}$} & \multirow[t]{2}{*}{ Supply } \\
\hline PRICE & $\mathbf{A}$ & B & $\mathrm{C}$ & D & $\mathbf{E}$ & & & \\
\hline 20 & 1 & 0 & 5 & 8 & 1 & 15 & 15 & 26 \\
\hline 19 & 2 & 0 & 5 & 0 & 1 & 8 & 23 & 26 \\
\hline 18 & 10 & 0 & 5 & 3 & 12 & 30 & 53 & 26 \\
\hline 17 & 13 & 26 & 11 & 15 & 12 & 77 & 130 & 26 \\
\hline
\end{tabular}
a. What is the market-clearing price?
b. What is the profit of player $\mathrm{B}$ ?
c. What is the profit of player $\mathrm{D}$ ? 